\title{
THE COOLING RATES AND PARENT PLANETS OF SEVERAL IRON METEORITES
}

John A. Wood
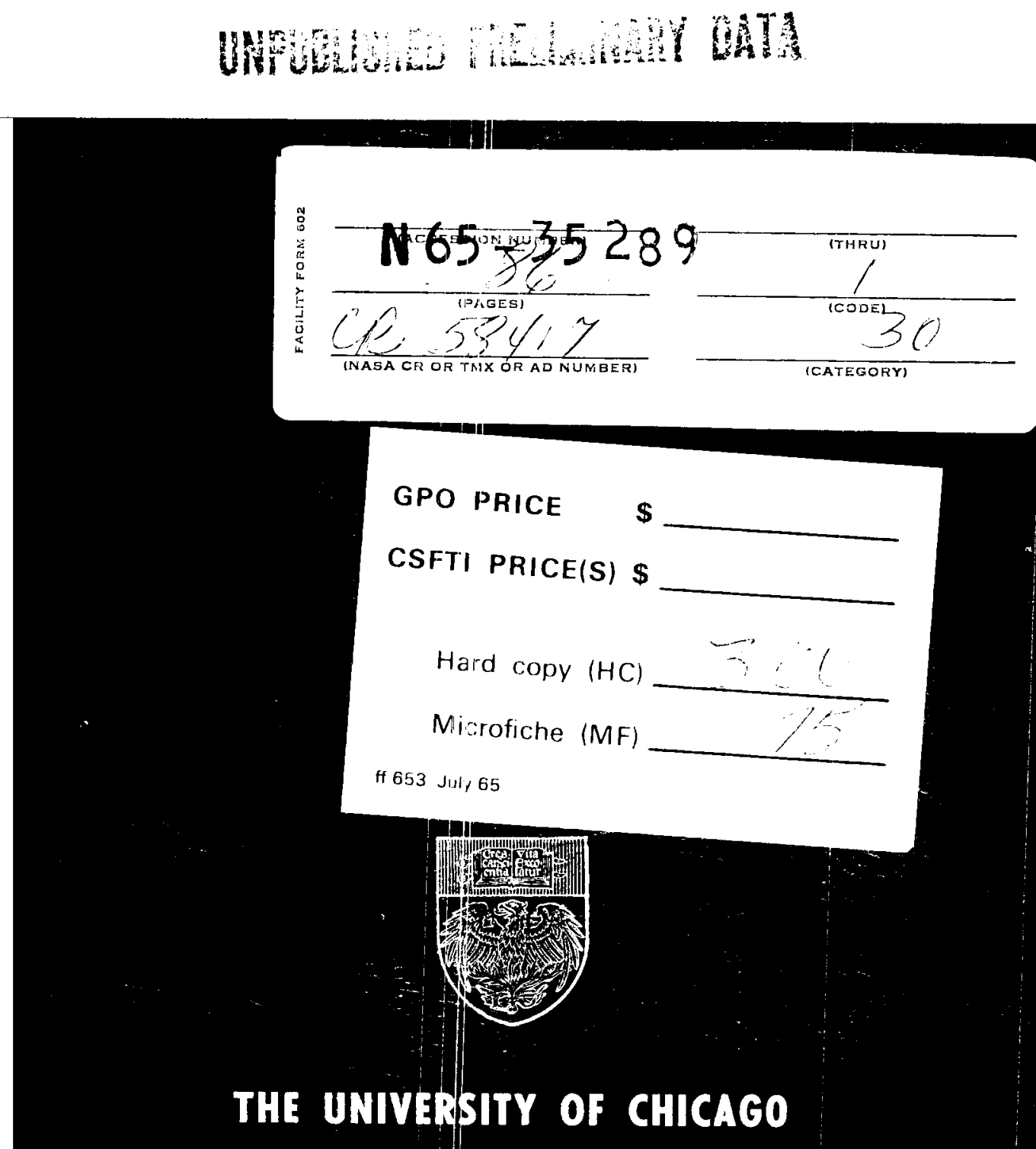

THE FIRICO FERHL INSTITUTE FOR NUCLEAR STUDIES 
THE COOLING RATES AND PARENT PLANETS OF SEVERAL IRON METEORITES

\author{
John A. Wood \\ Enrico Fermi Institute for Nuclear Studies \\ University of Chicago; Chicago, Illinois
}

\author{
Submitted to \\ Icarus \\ August , 1964
}

NASA Grant NsG-366 Research

NSF Grant No. G-14298 
Abstract

The Widmanstatten structure in octahedrites can be understood in detail and quantitatively as the result of solid-state transformations that would occur in slowly cooling Ni-Fe alloys. High pressure is not needed to account for the presence of plessite instead of Widmanstatten structures in those meteorites where $\mathrm{Ni}>\approx 13 \% \mathrm{Ni}$, or in those regions of octahedrites where $-22 \%>\mathrm{Ni}>-13 \%$. Experiments show that Ni-Fe alloys tend to remain in the form of metastable $\gamma$ phase when cooled from the $\gamma$ stability field into the $\alpha+\gamma$ field, but transform promptly from the metastable $\alpha_{2}$ state into $\alpha+\gamma$. Plessite was formed when meteoritic alloys supercooled as metastable $\gamma$ phase to such an extent that they transformed to $\alpha_{2}$; thereafter they decomposed to fine, non-Widmanstutten $\alpha+\gamma$, i.e., plessite.

Electron probe profiles were made of the characteristic $\mathrm{Ni}$ diffusion gradients in taenite-plessite regions of eleven octahedrites. A digital computer program was set up to generate artificial diffusion gradients by solving the equation for diffusion of $\mathrm{Ni}$ in $\gamma$ alloys under differing circumstances, i.e., for systems with various bulk Ni contents, nucleation spacings, nucleation temperatures, and cooling rates. It was found possible to artificially duplicate the measured gradients only if an $\alpha /(\alpha+\gamma)$ phase boundary somewhat different from the generally accepted Owen and Liu (1949) version was used in the program. Results of a single annealing experiment supported use of this amended boundary . 
Comparisons of computed and measured structures permitted conclusions to be drawn about thermal histories of the octahedrites studied. Most cooled to $\sim 100^{\circ} \mathrm{C}$ beneath the $\gamma /(\alpha+\gamma)$ boundary before Widmanstatten structure was precipitated. A correlation between cooling rates, structural types and probably Ga-Ge groups appears to exist. The medium, fine and finest octahedrites Grant, Trenton, Duchesne, Santa Apolonia and Bristol cooled at $\sim 10^{\circ} \mathrm{C} / \mathrm{million}$ years. The coarse and coarsest octahedrites Arispe, Cañon Diablo and Odessa, and the medium octahedrite Toluca cooled at $-1^{\circ} \mathrm{C} / \mathrm{million}$ years. Anoka, a finefinest octahedrite, cooled at an anomalous $1^{\circ} \mathrm{C} / \mathrm{million}$ years. These are cooling rates appropriate to the centers of asteroids, $50-90 \mathrm{~km}$ in radius for the first group and $130-260 \mathrm{~km}$ in radius for the second. Two Ni-rich ataxites studied (Piñon, Monahans) precipitated scattered kamacite crystals under circumstances of very rapid cooling, excessive supercooling, or both. 
The Cooling Rates and Parent Planets of Several Iron Meteorites

John A. Wood

E. F. F. Chladni (1794) suggested the meteorites are debris from an alien planet destroyed by explosion or collision, and the idea has been almost universally held since his time. The iron meteorites, which comprise about 5\% of meteorites seen to fall to earth, are usually thought to be remnants of a core of nickel-iron in the parent planet, analogous to Earth's highdensity core. Such a core must have been the product of melting (and perhaps reduction of iron silicates to the metallic state) in the interior of the planet, with the denser liquid iron fraction settling to the center of the body, followed by slow cooling and crystallization.

About 600 iron meteorites, mostly finds rather than falls, are preserved in the museums of the world. Of these, some $80 \%$ contain a curious internal structure. Systems of parallel plates of kamacite ( $\alpha$ nickel-iron, body-centered-cubic), roughly a millimeter thick, run through the meteorite. There are four such systems, paralleling the faces of an octahedron and intersecting in an intricate way. The kamacite contains $6.5-7.5$ weight per cent nickel. Coating the surfaces of the kamacite plates is a thin layer of taenite ( $\gamma$ nickel-iron, face-centered-cubic) of variable but high nickel content, up to about 45 per cent. The polyhedral spaces between the taenite-coated kamacite plates are filled largely with plessite, which is not another alloy but a 
simple mixture of fine-grained kamacite and taenite. Plessite is highly variable in structure and grain size. Other minerals occur in iron meteorites in subordinate amounts -- troilite, Fes; schreibersite, $(\mathrm{Fe}, \mathrm{Ni})_{3} \mathrm{p}$; cohenite, $(\mathrm{Fe}, \mathrm{Ni})_{3} \mathrm{C}$, and graphite; but only the nickel-iron alloys will be treated in this paper.

The alloy structure just described can be observed in two dimensions (Fig. 6A) by slicing an iron meteorite, polishing the sawed face, and etching it with dilute nitric or picric acid. The geometry of the pattern revealed depends, of course, on the angle at which the reference octahedron was sectioned. The structure is named after Count Alois de Widmanstatten, director of the Imperial Porcelain Works in Vienna, who first observed it in 1808, in the Hraschina meteorite. Irons containing Widmanstatten structure are called octahedrites, after the geometry of the kamacite plates, and are subdivided according to thickness of the plates (Table 1).

Several studies of octahedrites have recently been made, in which electron probe microanalyzers were used to make profiles of nickel content across the Widmanstatten pattern (Yavnel, Borovski, Ilin and Marchukova, 1958; Maringer, Richard and Austin, 1959; Feller-Kniepmeyer and Uhlig, 1961). These have shown that immediately adjacent to kamacite the taenite is very high in nickel content, but that nickel content decreases smoothly with distance from the interface. Plessite abuts on the lownickel side of taenite zones; its profile is highly erratic because it contains both high- and low-nickel phases, but the 
local average nickel content of the plessite, where this can be estimated, continues the steady decline begun in the taenite. At a point approximately equidistant from all bounding kamacite regions, nickel content reaches a minimum. Thus, as a complete taenite-plessite-taenite structure is traversed, an approximately M-shaped profile is traced out (numerous examples can be seen in Figs. 11-16). Since frequent reference will be made to profiles of such structures, the term "M-profiles" will be adopted in this paper for brevity.

1. FORMATION OF THE WIDMANSTÄTTEN STRUCTURE

Obviously the Widmanstatten structure formed in iron meteorites as they cooled from an initially homogeneous liquid state, and many attempts have been made to explain the structure in terms of the binary iron-nickel phase diagram, beginning with the work of Osmond and Cartaud (1904). The phase diagram (Fig. 1) contains an $\alpha+\gamma$ (i.e., kamacite plus taenite) field below $910^{\circ} \mathrm{C}$, and most writers have assumed the Widmanstatten structure formed, via reaction and diffusion in the solid state, as the cooling core of the parent meteorite planet passed through this field.

The most straightforward way for this to have happened is as follows (Derge and Kommel, 1937; Perry, 1944). Consider a large single crystal of, say, $8 \% \mathrm{Ni}$ alloy, at a sufficiently high temperature to be in the $\gamma$ state. When it cools to below $712^{\circ} \mathrm{C}$ it enters the $\alpha+\gamma$ field, and under equilibrium condi- 
tions crystals of $\alpha$ phase of composition $A^{\prime}$ in Fig. 1 are precipitated from the $\gamma$ alloy. The $\alpha$ crystals tend to nucleate in the form of plates or lamellae, the (110) lattice planes of which are parallel to the octahedral $\{111\}$ planes of the original $\gamma$ crystal, probably because this mode of transformation requires the least rearranging of the original $\gamma$ lattice. Young (1926) has demonstrated that this orientational relationship exists between kamacite and taenite in the octahedrites.

As cooling proceeds, the equilibrium $\mathrm{Ni}$ content of $\alpha$ phase increases, following $A^{\prime} B^{\prime} C^{\prime}$ in Fig. 1. Similarly, $\gamma$ phase increases along $\mathrm{ABC}$. Both phases can increase their Ni content in a system of constant total $\mathrm{Ni}$ content only if the amount of low-Ni phase $(\alpha)$ increases at the expense of the highNi phase. Thus the kamacite plates, infinitesimally thin at $712^{\circ} \mathrm{C}$, grow in thickness with decreasing temperature, as schematically depicted in the right half of Fig. 1 .

Nickel atoms must move by solid diffusion from the $\alpha / \gamma$ interface (where they are being made available by the transformation of high-Ni $\gamma$ into low-Ni $\alpha$ ) into the interiors of both phases, in order to maintain equilibrium compositions in the latter as the system cools. But coefficients of solid diffusion are strongly temperature dependent, and a temperature is eventually reached at which diffusion is too sluggish to allow $\mathrm{Ni}$ to reach the interiors of $\gamma$ regions. With further cooling, the distance $\mathrm{Ni}$ can effectively travel in $\gamma$ phase continues to shorten, and the cumulative effect is to create 
$\gamma$ regions with inhomogeneous $\mathrm{Ni}$ content, such that the closer a point is to an $\alpha / \gamma$ boundary, the higher is its $N i$ content and the closer it is to the equilibrium composition (e.g., the $500^{\circ}$ profile in the right half of Fig. 1). (Ni diffusion becomes sluggish in $\alpha$ phase at a considerably lower temperature than in $\gamma$ phase.)

Eventually the $\mathrm{Ni}$-poor centers of these $\gamma$ regions are so badly out of equilibrium that they break down into a finegrained mixture of equilibrium kamacite and taenite, i.e., plessite. All characteristics of the Widmanstatten structure have been accounted for.

H. H. Uhlig (1954) has pointed out some puzzling inconsistencies in this scheme. Uhlig cites laboratory evidence that $\gamma$ alloys of up to $34 \% \mathrm{Ni}$ transform quite readily into $\alpha+\gamma$ when they are cooled, even when the cooling rate is rapid. How, then, did the low-Ni plessite regions form? As soon as sluggish diffusion left the center of a $\gamma$ crystal with slightly less than the equilibrium concentration of $\mathrm{Ni}$, it should have decomposed, not into plessite but into a sub-Widmanstatten structure. Yet the smooth form of most M-profiles shows they remained entirely in the form of supercooled $\gamma$ phase while the range of $\mathrm{Ni}$ diffusion became smaller and smaller. Plessite must have appeared at a late stage. Also, why don't iron meteorites with more than $13 \% \mathrm{Ni}$ contain widmanstatten structure? Any iron with less than $34 \% \mathrm{Ni}$ should have developed Widmanstatten structure, but in fact almost all irons with more than $13 \% \mathrm{Ni}$ 
belong to the class of nickel-rich ataxites. They consist for the most part of plessite, but some contain scattered kamacite plates (Fig. 10D).

Uhlig's answer to this paradox is that the Widmanstutten structure developed during cooling under great pressure. Pressure has the general effect of shifting the phase diagram downward to lower temperatures. At one atmosphere pressure, alloys with over $34 \% \mathrm{Ni}$ content fail to transform to $\alpha+\gamma$ on cooling, presumably because they cross the $\gamma /(\alpha+\gamma)$ boundary at too low a temperature; according to the phase diagram, the limiting temperature is $460^{\circ} \mathrm{C}$. Uhlig estimates that about $10^{5}$ atmospheres of pressure would shift the diagram to such an extent that all alloys with greater than $13 \% \mathrm{Ni}$, no longer $34 \% \mathrm{Ni}$, would cross the $\gamma /(\alpha+\gamma)$ boundary at less than $460^{\circ} \mathrm{C}$, and thus would fail to transform. (Ringwood and Kaufman [1962] have made more precise thermochemical calculations of the effect of pressure on the $\mathrm{Fe}-\mathrm{Ni}$ phase diagram; they conclude that $3-6 \times 10^{4}$ atmospheres would shift the phase diagram by the desired amount.) Uhlig suggests that all of what is now plessite remained in the form of supercooled $\gamma$ phase until the parent meteorite planet was disrupted. Loss of pressure caused these regions to transform to $\alpha_{2}$-phase (discussed below), which subsequently decomposed to a fine-grained mixture of $\alpha$ and $\gamma$ phase, i.e., plessite.

This interpretation of the Widmanstatten structure is almost certainly incorrect. The pressures derived by Uhlig and 
Ringwood and Kaufman require the iron meteorites to have formed inside a planet of substantial size. Many difficulties are associated with the idea of deriving any of the meteorites from large planets; these are discussed by Anders (1964). Uhlig's model requires the interior of a large planet to cool from the melting point of nickel-iron (about $1500^{\circ} \mathrm{C}$ ) to $400^{\circ} \mathrm{C}$ within the age of the solar system. But the thermal inertia of a planet as large as Uhlig requires is too great to permit this degree of cooling. Urey and Donn (1956) noted this inconsistency, and Allan and Jacobs (1956) amplified upon it.

The difficulty is illustrated in Fig。2, where several planetary thermal histories are presented. A digital computer was used to obtain these numerical solutions of the heatdiffusion equation (Appendix I). A planet at least $1290 \mathrm{~km}$ in radius is needed for Uhlig's model; this would have a central pressure of $3 \times 10^{4}$ atmospheres (assuming a density of 3.6 gms $/ \mathrm{cm}^{3}$ ), the minimum acceptable pressure according to Ringwood and Kaufman's calculations (1962). Curve A in Fig. 2 is the cooling history of a $1290 \mathrm{~km}$ planet containing no radioactive heat sources, the initial temperature of which was just adequate to melt nickel-iron. It would not have cooled to beneath $1000^{\circ} \mathrm{C}$ during the age of the solar system. And the assuimption of no radioactive heating is unreasonable; if the planet contained $\mathrm{K}, \mathrm{U}$ and $\mathrm{Th}$ in the same amounts as the most abundant class of stony meteorites, the chondrites, then the interior of the planet would have heated, not cooled (curves $B$ and $C$ ). 
How, then, are the inconsistencies pointed out by Uhlig explained? Why don't meteorites with over $13 \% \mathrm{Ni}$, and regions of octahedrites in the same compositional range, contain Widmanstatten structure instead of plessite? The inconsistencies are based on the observation that alloys with up to $34 \% \mathrm{Ni}$ transform readily into $\alpha+\gamma$ in the laboratory. Here Uh1ig refers to the experiments of Mehl and Derge (1937) and Derge and Kommel (1937), in which alloys of $27-34 \% \mathrm{Ni}$ were cooled from the melt to room temperature in, at most, a few hours. These were found to possess fine Widmanstatten structures, sometimes visible to the naked eye, and X-ray diffraction spectra showed them to contain both $\alpha$ and $\gamma$ phase. Artificial Widmanstatten structure of this type had first been obtained by Benedicks (1910).

It appears, however, that these results were highly misleading. A much better understanding of the metastable $\alpha_{2}$ phase of nickel-iron has been reached since 1937 (Jones and Pumphrey, 1949; Kaufman and Cohen, 1956). $\quad \alpha_{2}$ has a distorted body-centeredcubic lattice, and is produced when $\gamma$ nickel-iron is quenched. It is very similar to martensite in the Fe-C system, but most writers prefer to reserve the term martensite for the $\mathrm{Fe}-\mathrm{C}$ system. Owen and Sully (1941) use the name metakamacite. Conditions under which $\alpha_{2}$ exists are shown in Fig. 3 。 When a quenched $\gamma$ alloy of up to $34 \% \mathrm{Ni}$ crosses $\mathrm{M}_{\mathrm{S}}$, it begins to transform to $\alpha_{2}$ phase. Transformation is not completed until temperature has dropped about $100^{\circ}$ below $\mathrm{M}_{\mathrm{S}}$. The transformation is polymorphic; it does not entail lattice diffusion, and proceeds instantly when $M_{S}$ is crossed, even when $M_{S}$ lies at sub-zero temperatures. Note that while a maximum of about $8 \%$ 
$\mathrm{Ni}$ is soluble in $\alpha$ phase (kamacite), $\alpha_{2}$ can contain up to $34 \%$.

The system exhibits a hysteresis, such that with increasing temperatures, $\alpha_{2}$ does not begin to revert to $\gamma$ until $\mathrm{A}_{\mathrm{S}}$ (Fig. 3) is crossed. The transformation is completed at some point above $A_{S}$. The positions of $M_{S}$ and $A_{S}$ do not appear to depend on rate of cooling or heating.

A very important paper by Allan and Earley (1950) showed that it is not necessary to quench $\gamma$ alloys to obtain $\alpha_{2}$ phase. Contrary to the conclusions of Derge, Mehl and Kommel, $\gamma$ alloys, even if cooled very slowly, fail to transform to $\alpha+\gamma$ on crossing the $\gamma /(\alpha+\gamma)$ boundary. They remain in the $\gamma$ state and, at lower temperatures, transform to $\alpha_{2}$.

The following cooling experiment was conducted by the writer. Alloys with $8 \%$ and $18 \% \mathrm{Ni}$, remainder $\mathrm{Fe}$, were vacuum melted and quenched. They were then sealed in quartz glass tubes in vacuo, annealed at $1000^{\circ} \mathrm{C}$ for 3 days, the temperature was dropped to $800^{\circ} \mathrm{C}$, and thenceforward an automatic temperature controller allowed them to cool at a steady rate of $-6^{\circ} \mathrm{C} / \mathrm{day}$. In about four months the alloys reached room temperature. Both appeared to contain two phases. The $18 \%$ alloy had developed a Widmanstatten structure (Fig。6B) quite similar to those in Derge, Mehl and Kommel's photomicrographs, but rather dim in appearance, even after intensive etching. (The clarity of Fig. 6B was achieved by use of a very high contrast emulsion, 
gamma about 4.5. Gamma for other photographs in this paper was about 1.3.) Structure in the $8 \%$ alloy, distinctly revealed by etching, was irregular and coarse.

Electron microprobe traverses, however, showed that both alloys were homogeneous in composition (Fig. 11); neither had precipitated low-Ni $\alpha$ phase on a resolvable scale. X-ray diffraction patterns of both alloys contained only the lines of $\alpha_{2}$ phase. The "Widmanstatten pattern" in the writer's $18 \%$ alloy, as well as those observed by Derge, Mehl and Kommel, resulted from the precipitation of plates of $\alpha_{2}$, not $\alpha$, along $\{111\}$ planes in the host $\gamma$ phase.

Derge, Mehl and Kommel were particularly successful in producing Widmanstatten structure in a $27 \% \mathrm{Ni}$ alloy. Such an alloy crosses the $\mathrm{M}_{\mathrm{S}}$ curve at about $50^{\circ} \mathrm{C}$, and at room temperature is only partly transformed to $\alpha_{2}$. It would etch distinctly because it contains two phases; etching had relatively little effect on my $18 \%$ alloy because it had converted entirely to $\alpha_{2}$. X-ray diffraction spectra of the $27 \%$ alloy would contain lines of $\gamma$ and $\alpha_{2}$; the only difference between the spectra of $\alpha_{2}$ and $\alpha$ is that the lines are broader and more diffuse in $\alpha_{2}$, and Derge, Meh1 and Kommel probably failed to make the distinction, the significance of which was little appreciated in 1937 . Finally, we can understand why alloys with more than $34 \% \mathrm{Ni}$ failed to yield "Widmanstatten structure" for these workers; not because they cross the $\gamma /(\alpha+\gamma)$ boundary at less than $460^{\circ} \mathrm{C}$, as Uhlig assumes, but because $34 \%$ is the limiting content of $\mathrm{Ni}$ for $\alpha_{2}$ phase (Fig. 3). 
We can see, then, that cooling $\gamma$ alloys are very reluctant to transform to $\alpha+\gamma$. Owen and Liu (1949) accomplished the transformation in those runs that yielded them $\alpha+\gamma$ data points in the part of their phase diagram where $\mathrm{Ni}$ exceeds $27 \%$, but all their samples had been cold-worked, the powder specimens by filing and the lump specimens by hammering. Lattice distortions introduced by cold work greatly enhance recrystallization and the nucleation of new phases. Owen and Liu annealed their powders at $600^{\circ} \mathrm{C}$ for $11 / 2$ days before beginning their runs, but this must not have removed all the beneficial effects of cold working. Certainly some extraordinary effect assisted in the $\gamma \rightarrow \alpha+\gamma$ transformation in this case, for according to our knowledge of the diffusion coefficient of $\mathrm{Ni}$ in $\gamma$ alloys, $\mathrm{Ni}$ could not have diffused as far as one Angstrom unit during their $350^{\circ} \mathrm{C}$ experimental runs.

The demonstrated reluctance of non-cold-worked $\gamma$ alloys to transform to $\alpha+\gamma$ on cooling removes the inconsistency noted by Uhlig (1954), and restores to plausibility the simple process outlined at the beginning of this section, by which the Widmanstatten structure could have formed in a system cooling under negligible pressure. The iron meteorites undoubtedly cooled very slowiy by human standards, so in alloys crossing the $\gamma /(\alpha+\gamma)$ boundary at high temperatures time must have overcome the reluctance of $\alpha$ phase to nucleate, and the Widmanstatten structure began to crystallize at or somewhere beneath the $\gamma /(\alpha+\gamma)$ boundary. The data in Section 4 indicate that nucleation tends to occur $80^{\circ}$ to $120^{\circ}$ below the $\gamma /(\alpha+\gamma)$ 
boundary. A limiting temperature certainly exists, however, beneath which not even geologic periods of time would suffice for the nucleation of Widmanstatten structure. A value for the limiting temperature of about $550^{\circ}$ would mean alloys with more than $13 \% \mathrm{Ni}$ were prevented from developing Widmanstatten structure, if allowance is made for the fact that nucleation occurs not at the $\gamma /(\alpha+\gamma)$ boundary but $100^{\circ}$ or so below it. This would provide the cutoff in $\mathrm{Ni}$ content required by Uhlig.

R. Vogel (1925, 1951) has offered an entirely different explanation of the Widmanstatten structure, namely that it formed as the metal crystallized from the molten state, in the small $(\alpha+$ melt $)$ and $(\alpha+\gamma)$ fields that can be seen in Fig. 1 above $1400^{\circ} \mathrm{C}$. Actually Vogel requires the ternary Fe-Ni-P system to explain the Widmanstatten structure. He is able to account for all the features of the structure in a qualitative way, but uncertainties in the phase diagram make it impossible to apply quantitative tests to his hypothesis. No evidence exists that kamacite crystallizing from a melt would form an octahedral array of plates with the residual melt between them, as his model requires. The octahedral geometry of the Widmanstatten structure is much more easily understood in terms of precipitation of $\alpha$ phase, in the sulid state, along the octahedral $\{111\}$ lattice planes of host $\gamma$ alloy.

The most serious difficulty with Vogel's hypothesis, however, is obvious in Fig. 1. His two-phase structure, once formed, should convert entirely to $\gamma$ phase during cooling, and 
unless the cooling is very rapid, Ni diffusion should level out all compositional differences and obliterate any primary Widmanstatten structure. Vogel counters this objection by pointing out that increasing phosphorus content causes the high- and low-temperature $\alpha+\gamma$ fields to expand and, at about $0.6 \% \mathrm{P}$, to merge into a single $\alpha+\gamma$ field. Octahedrites are not known to contain more than $0.5 \% \mathrm{P}$ (actually $0.2 \%$ is a more typical value), but Vogel points out that even at $0.5 \% \mathrm{p}$, the temperature interval between the two $\alpha+\gamma$ fields is reduced to $200^{\circ} \mathrm{C}$, compared with $700^{\circ}$ in the phosphorus-free system.

Vogel depends on this reduced interval of instability, and on an apparent sluggishness of solid-state reaction in P-rich alloys, to maintain the octahedrites metastably in a two-phase state until they cool into the low-temperature $\alpha+\gamma$ field. This seems unlikely, however. The writer sealed small slices of the Grant octahedrite, complete with their compliment of meteoritic phosphorus, in evacuated glass tubes and included them in the furnace experiment described above, where temperature was decreased by $6^{\circ} \mathrm{C}$ per day from $800^{\circ}$ to room temperature. They were entirely in the $\alpha_{2}$ state after the experiment. Electron probe profiles showed that $\mathrm{Ni}$ diffusion, evidently while the specimens were in the $\gamma$ staie, had greatly diminished the $\mathrm{Ni}$ content of the regions that had been taenite to start with; concentration gradients showed $\mathrm{Ni}$ had flowed in both directions, into regions that were originally kamacite and others that were originally plessite. Profiles over plessite regions are often jagged (Fig. 15, profile 65), but 
were smooth when run over comparable regions in the heated specimen of Grant; they had been homogenized by diffusion. It is only reasonable to suppose the same thing would have happened to Grant as it cooled through the $\gamma$ field in the parent meteorite planet.

Returning to the simple concept of producing Widmanstatten structure by slow cooling, at low pressure, through the lowtemperature $\alpha+\gamma$ field, it is possible to investigate this process quantitatively. The Fe-Ni phase diagram and the coefficients of diffusion of $\mathrm{Ni}$ in $\alpha$ and $\gamma$ alloys are known with considerable certainty. In principle, it should be possible, by use of Fick's diffusion equation, to watch the Ni concentration at various points in a hypothetical $\gamma$ alloy crystal as it is cooled and as the equilibrium $\mathrm{Ni}$ value increases and diffusion becomes more and more sluggish. This could be done for various cooling rates, with the expectation that when the cooling rate of the parent meteorite planet was chanced upon, the final hypothetical $\mathrm{Ni}$ profile obtained would match the M-profiles measured in octahedrites. Such will be the purpose of this paper.

\section{MICROPROBE PROFILES}

The eleven octahedrites and three nickel-rich ataxites listed in Table 2 were studied. Small plates were cut from each; before mounting, the edges of the octahedrite plates were polished and etched, so the angles at which their various struc- 
tures intersected the main surface could be determined and - recorded. After these were mounted, polished and picral etched, taenite-plessite structures suitable for profiling were selected and photographed. These are shown in Figs. 710, together with dip symbols showing the angle at which the kamacite-taenite interfaces intersect the polished surface. (The sense of the angle is such that an object sliding down the interface would move as the arrow points.)

Reference marks were scratched near the paths of intended profiles with a steel needle, and their positions marked on a set of working photographs. The samples were then repolished with . $05 \mu$ alumina on a cloth lap, so the etched surfaces were removed but the reference marks retained. Using the reference marks, the working photographs and the calibrated traversing screws on the microprobe, it was possible to move each sample under the electron beam so as to perform the numbered traverses marked in Figs. $6-10$.

Analysis was performed with an ARL electron microprobe in the Department of Geophysical Sciences, University of Chicago. $27 \mathrm{KV}$ electrons were focussed on the specimen surface; X-radiation emitted impinged on a LiF crystal monochromator, from which the $\mathrm{Ni} \mathrm{k}_{\alpha}$ characteristic radiation was passed to an Exatron sealed proportional counter with a Be window, containing Ne gas. Profiles of $\mathrm{Ni} \mathrm{k}_{\alpha}$ counting rate were traced on chart paper as the specimens were moved under the beam, at a steady 
rate. These appear in Figs. 11-16, numbered in correspondence with their paths in Figs. 6-10.

A series of vacuum-melted $\mathrm{Fe}-\mathrm{Ni}$ alloys were used as standards. These showed the response of the instrument to be essentially linear in the range of interest, i.e., through 30\% Ni (Fig. 4). Specimens and standards were run alternately in the probe, and peak heights generated by the latter were used to calibrate the specimen profiles. The counting rate a particular standard produced usually varied little during a run, but in a few cases the instrument's beam current and hence the counting rate decreased or increased markedly during the run. Profiles in Figs. 11-16 generated under these circumstances can be recognized by their non-horizontal calibration lines, which are linear interpolations between standards run before and after the specimen. Nickel concentrations below $30 \%$, where the structure was adequately resolved, are accurate to $\pm 0.5 \% \mathrm{Ni}$ or $\pm 4 \%$ of the $\mathrm{Ni}$ concentration reported, whichever is greater.

The effective probe beam diameter was $2-3 \mu$. However, structures larger than this sometimes were not adequately resolved if a large displacement of the recorder pen was required, because of pen lag and a relatively rapid scan speed $(98 \mu / \mathrm{min})$. For this reason, the $\mathrm{Ni}$ maximum reported in taenite at the leading edge of M-profiles (i.e., as the beam passed abruptly from kamacite into high-Ni taenite) is almost always lower than that reported in taenite at the trailing edge. 
In most of the profiles in Figs. 11-16, the kamacite - is as much as $1 \%$ lower in $\mathrm{Ni}$ content at kamacite-taenite interfaces, than it is in the interior of large kamacite crystals. This effect is especially well displayed in the Anoka profiles (Nos.66, 67). It was first described by Agrell, Long and Ogilvie (1963), and might appropriately be referred to as the "Agrell effect". Because of recorder pen lag, as noted above, the Agrell effect is usually more conspicuous at the leading edge of M-profiles than at the trailing edge.

\section{CALCULATION OF THEORETICAL M-PROFILES}

The problem at hand is to solve Fick's equation for diffusion of $\mathrm{Ni}$ from the surface to the interior of a taenite crysta1, as temperature decreases at various constant or changing rates. Nickel concentration at the surface is assumed always to be the equilibrium value, hence increases as temperature falls, following the $\gamma /(\alpha+\gamma)$ boundary of the Fe-Ni phase diagram. We must take into account that the $\alpha / \gamma$ boundary encroaches on the taenite crystal during the process, continually destroying the high-Ni portion of the $\mathrm{Ni}$ concentration profile, and reducing the size of the crystal. The problem is intractable by analytical methods, but can easily be set up for solution by a digital computer under a wide variety of initial and boundary conditions. 
The writer has worked sporadically on this project since 1961. During that time preliminary results were alluded to in publications (Wood, 1962, 1963) and at the 1963 Gordon Research Conference on the Chemistry and Physics of Space; and during that time the IBM computers employed evolved from model 709 to 7090 to 7093 . Some features of the program used are given in Appendix II.

Algebraic equations fitted to the significant portions of the $\alpha /(\alpha+\gamma)$ and $\gamma /(\alpha+\gamma)$ phase boundaries of Owen and Liu (1949) were written into the program, and most recently the expression for diffusion of $\mathrm{Ni}$ in gamma phase determined by Goldstein (1964) has been used. Goldstein's diffusion coefficient is based on microprobe profiles run across laboratory diffusion couples, an analytical method of far greater sensitivity than that employed by Wells and Mehl (1941); the only method available to those authors was to machine thin layers from the couple, parallel to the original interface, and analyze them chemically. Goldstein's diffusion coefficient is an order of magnitude smaller than Wells and Mehl's in the temperature range where the Widmanstatten structure formed. It is in substantial agreement with the coefficient found by MacEwan, MacEwan and Yaffe, who counted radioactive $\mathrm{Ni}^{63}$ in their diffusion couples.

Attempts to generate artificial M-profiles with this program were disappointing. Let us try to duplicate the profile in Fig. 17A, for example -- this is profile 18 from the Odessa 
octahedrite. The bulk Ni content of Odessa, and the distance -between centers of adjacent kamacite lamellae whose growth impinged on the structure of interest are entered as input. Nucleation is assumed to have occurred as soon as the alloy crossed the $\gamma /(\alpha+\gamma)$ boundary, at $712^{\circ} \mathrm{C}$. Diffusion is allowed to proceed until the temperature drops to $395^{\circ} \mathrm{C}$, by which time the kamacite composition, according to the phase diagram of Owen and Liu (1949), has reached $6.8 \% \mathrm{Ni}$. This is approximately the $\mathrm{Ni}$ concentration of kamacite in octahedrites, and it appears reaction must have ceased at about this point, or kamacite in octahedrites would contain more $\mathrm{Ni}$ than it does. Here the computation is terminated, and the final $\mathrm{Ni}$ profile printed as output.

The results, for several assumed constant cooling rates, are plotted in Fig. 17B. None are similar to the real M-profile from Odessa. The $1 \% \mathrm{~m} . \mathrm{y}$. profile has roughly the same nickel concentration in its center as the Odessa profile, but the sloping diffusion borders of the Odessa profile are missing. This difficulty plagued all attempts to match meteoritic Mstructures, and although many exotic non-linear cooling histories were tested, none improved the situation.

It is not hard to see why this happens. Ni diffusion in $\gamma$ phase effectively ceases well before the computation ends. Yet boundary encroachment continues until the end, in order to supply Ni to $\alpha$ phase, which according to the phase diagram must continue to increase its $\mathrm{Ni}$ content. The $\mathrm{Ni}$ increase in a phase is small, 
but the amount of $\alpha$ phase in the system is large, so substantial boundary encroachment must occur to supply the Ni. This destroys the sloping diffusion borders at a time when they can no longer be restored, because diffusion has effectively ceased.

It seems that kamacite cannot have continued to absorb $\mathrm{Ni}$ after diffusion in $\gamma$ ceased, or we would not see M-shaped profiles in octahedrites. In the computation above, it was assumed that $\mathrm{Ni}$ would be able to diffuse into kamacite down to a temperature of $395^{\circ} \mathrm{C}$. This should be checked.

The $\mathrm{Ni}$ contents at the centers of the profiles in Fig. 17B are dependent largely on the diffusion coefficient of $\mathrm{Ni}$ in $\gamma$ phase, and are affected only indirectly by the behavior of $\alpha$ phase. Unless the diffusion coefficient or the $\gamma /(\alpha+\gamma)$ boundary used are wrong, then, Odessa's cooling rate must have been of the order of $1^{\circ} \mathrm{C}$ per million years, since approximately the same amount of nickel succeeded in penetrating to the center of our malformed theoretical $1^{\circ} / \mathrm{m} . \mathrm{y} \cdot$ profile as penetrated the Odessa structure. Using this cooling rate and the diffusion coefficient of $\mathrm{Ni}$ in $\alpha$ phase (Hirano, Cohen and Averbach, 1961), we can determine the approximate distance nickel is capable of diffusing at various temperatures. This was done by computing $(D t)^{1 / 2}$ for $t=2 \times 10^{7}$ years (the time during which temperature falls by $20^{\circ} \mathrm{C}$ ), at $20^{\circ}$ intervals (Table 3). Kamacite plates in Odessa are 2000 - $3000 \mu$ thick, and we see that nickel ceased to be able to reach their centers at roughly $500^{\circ} \mathrm{C}$. 
But according to the phase diagram, equilibrium $\alpha$ phase at $500^{\circ} \mathrm{C}$ contains only $5.2 \%$ nickel; yet we know the centers of Odessa kamacite plates contain $6.6-7.0 \%$. This inconsistency makes it appear that the formation of the octahedrites was controlled by an $\alpha /(\alpha+\gamma)$ boundary that differs somewhat from Owen and Liu's. This need not be taken as criticism of the accuracy of the Owen and Liu phase diagram: the binary diagram is, after all, only an approximation to meteoritic systems; other elements undoubtedly influence the diagram to some extent. The ternary Fe-Ni-P diagrams of Vogel (1957) indicate a shift of the $\alpha /(\alpha+\gamma)$ boundary toward higher Ni concentrations, with increasing phosphorus content.

The $\alpha /(\alpha+\gamma)$ boundary, according to the Owen and Liu diagram, has a negative slope down to low temperatures. Accordingly, $\alpha$ phase should continue to increase in $\mathrm{Ni}$ content until lowering temperature checks diffusion. Kamacite plates should, therefore, have diffusion borders similar to those in taenite -- high-Ni regions near the $\alpha / \gamma$ interface, where diffusion continued to furnish $\mathrm{Ni}$ after it could no longer supply the interiors of the plates. They don't have them, of course, a curious fact that has attracted little attention. Kamacite is nearly uniform in composition, and the only diffusion borders observed are negative ones -- the Agrell effect, a deficiency in Ni near $\alpha / \gamma$ interfaces. We can only conclude that in the temperature range where diffusion in $\alpha$ phase halted, the $\alpha /(\alpha+\gamma)$ boundary was nearly vertical; the Agrell effect, in fact, indicates that it had actually reversed its slope while 
diffusion in the $10 \mu$ range was still possible.

It appears, then, that the formation of octahedrites was influenced by an $\alpha /(\alpha+\gamma)$ boundary that reached a maximum $\mathrm{Ni}$ value of about $6.8 \%$, at a temperature in the neighborhood of $500^{\circ} \mathrm{C}$. At lower temperatures it slopes back to smaller $\mathrm{Ni}$ levels. The upper portion of a curve meeting these requirements is plotted in Fig. 18 .

Results of a furnace experiment carried out by the writer support this amended $\alpha /(\alpha+\gamma)$ boundary. The experiment was initiated for a different purpose altogether, an attempt to produce plessite textures (Section 5); a temperature controller was not used, so fluctuations in line voltage caused the temperature to vary by $\pm 14^{\circ} \mathrm{C}$ (standard deviation of 24 temperature measurements). $8 \% \mathrm{Ni}$ alloys in the $\alpha_{2}$ state were sealed in evacuated glass capsules with $\mathrm{Ti}$ sponge getters and annealed at $663 \pm 14^{\circ} \mathrm{C}$. Although $\gamma$ alloys resist transformation indefinitely, $\alpha_{2}$ alloys transform readily to $\alpha+\gamma$. After 61 days of annealing, taenite crystals $20 \mu$ and more in dimension had developed, leaving residual kamacite areas $10 \mu$ or less in dimension. These were probed (profiles 3-7). In the 8\% binary alloy, the minimum nickel content encountered in $\alpha$ phase was $4 \%$, compared with $3.2 \%$ predicted by the Owen and Liu boundary. In a similarly annealed $8 \%$ alloy containing $0.2 \%$ P (a level typical of octahedrites), however, $\alpha$ phase contained $4.6 \% \mathrm{Ni}$. Both results are entered in Fig. 18, with account taken of microprobe and temperature uncertainties. The $0.2 \% \mathrm{p}$ result is in quite comfortable agreement with the amended $\alpha /(\alpha+\gamma)$ phase boundary. 
When this amended phase boundary is substituted for the Owen and Liu boundary in the computer program, M-profiles with healthy diffusion borders can be generated (Fig. 17C). If we use a cooling rate of $1.5^{\circ} \mathrm{C} / \mathrm{m} . \mathrm{y}$. and adjust the initial dimension of the diffusing structure slightly, a theoretical profile can be obtained that follows the real profile very closely (Fig. 17D).

\section{ANALYSIS OF DATA}

It is unnecessary and would be quite tedious to compute profiles to match all the microprobe scans in Figs. 11-16. To do this requires some juggling of either the effective initial dimension of the structure or the bulk Ni content of the meteorite; the final result is affected by both, in a complimentary way, and neither is known with great accuracy. Instead, I have concentrated on the relationship that exists between central $\mathrm{Ni}$ content of M-profiles and their widths, under a given set of conditions.

If we set a particular bulk $\mathrm{Ni}$ content, cooling rate and temperature of nucleation, and then carry out the diffusion calculation for a series of structures of varying effective initial dimensions, the M-profiles generated will be found to have central $\mathrm{Ni}$ concentrations and final dimensions that are related by a curve similar to the heavy line in Fig. 19. At its lower end, the curve is asmyptotic to a nickel concentration that equals the bulk nickel content assumed. This corresponds 
to the case of $\gamma$ areas so large that diffusion was not able to deliver any nickel at all to their centers. The dashed lines in Fig. 19 indicate how the curve is affected by changes in parameters. At lower bulk $\mathrm{Ni}$ contents, not only is the asymptotically approached $\mathrm{Ni}$ level lowered: but the sloping portion of the curve changes in form and steepens (A). At faster cooling rates, the curve retains its form but is shifted to the left (B). If we assume nucleation did not occur as soon as the $\gamma /(\alpha+\gamma)$ boundary was crossed, but that some degree of supercooling took place, the lower end of the curve is indented (C) -- the more supercooling, the greater the indentation.

The plan followed, then, was to generate a family of curves for various cooling rates and in some cases for various degrees of supercooling, at each of these bulk $\mathrm{Ni}$ contents: $7 \%, 8 \%, 9 \%, 11 \%, 16.5 \%$ 。 Points corresponding to the halfwidths and minimum $\mathrm{Ni}$ contents of the M-profiles in Figs. 1116 were then plotted against these (Figs.20, 21), and conclusions were drawn about the cooling history of each iron. Of course, the half-width - central $\mathrm{Ni}$ content relationship, and the shapes of M-profiles, are very closely related. The procedure outlined above is almost the same as seeking a single computed M-profile that matches the form of a large microprobed profile in each meteorite. The advantages of the method used are that data from a number of structures contribute to the conclusions drawn, lessening the chance of being mislead by: a 
structure with unsuspected geometrical peculiarities; and that considerations of effective initial dimension of the diffusing structure are eliminated.

Open circles plotted in Figs. 20 and 21 represent taeniteplessite areas adjacent to kamacite plates which appear, from metallographic examination, to have precipitated later than other kamacite. The effects of supercooling are to be expected in these. Black dots represent areas lacking evidence of supercooling.

Points representing very narrow profiles, which fall at the upper end of the half-width - central Ni content curves, were found to be the most reliable indicators of the cooling rate of the meteorite. The upper portions of the curves are less sensitive to uncertainty in bulk $\mathrm{Ni}$ content (actually, the parameter of interest is the difference between bulk $\mathrm{Ni}$ content and average $\mathrm{Ni}$ content of kamacite, since only this surplus of $\mathrm{Ni}$ is available for diffusion into $\gamma$ phase; this difference is very small and highly uncertain in coarse octahedrites like Cañon Diablo and Arispe). They are also unaffected by all but the most extreme degrees of supercooling. For this reason, extra weight was attached to the high-Ni data points in deducing cooling rates.

A cooling rate of $1^{\circ} \mathrm{C}$ per million years is indicated for Odessa, based largely on points 21 and 22 , which correspond to the small M-profiles having those numbers. The solid black 
dots fall somewhat below the $1 \% \mathrm{~m} . \mathrm{y}$. curve, indicating that some supercooling (about $100^{\circ} \mathrm{C}$ below the $\gamma /(\alpha+\gamma)$ boundary) occurred before Odessa's Widmanstatten structure was precipitated. Kamacite plates bounding profile 24 precipitated even later, at about $150^{\circ}$ of supercooling. Almost identical results were obtained for Toluca. Profiles $39 a$ and $39 b$ in Toluca are adjacent to small kamacite lamellae that precipitated in the low-Ni interior of a $\gamma$.region, obviously at a very late stage (Fig. 8G). Extreme supercooling, about $170^{\circ} \mathrm{C}$ below the $\gamma /(\alpha+\gamma)$ boundary, is indicated. Anoka also appears to have cooled at $1 \%$ m.y., but Widmanstatten structure appeared after only about $80^{\circ}$ of supercooling. These $1 \% \mathrm{~m}$. y. estimates are believed to be accurate to within a factor of two.

The Grant points are scattered, partly because of geometrical uncertainty for most profiles, which were taken across structures that intersect the surface at a low angle. Profiles 57 and 58, which were taken across a structure nearly perpendicular to the surface, point to a cooling rate of $5 \% \mathrm{~m} . \mathrm{y}$. Estimated uncertainty: $\mathrm{x} 3$.

Cañon Diablo and Arispe appear to have cooled at about 0.5 and $2^{\circ} \mathrm{C} / \mathrm{m} . \mathrm{y}$. respectively. Positions of computed curves to compare these meteorites against are uncertain, however, because the quantity (bulk nickel content minus kamacite nickel) is small and uncertain. Cooling rates cited are uncertain to within a factor of three. 
A cooling rate of $10^{\circ} / \mathrm{m} . \mathrm{y}$. is indicated for Duchesne, Santa Apolonia and Trenton, but for none of these was an adequate number of profiles taken. Estimated uncertainty is x2 for Duchesne, $x 3$ for the other two, each of which depends on the profile from a single small taenite crystal of uncertain geometry. Profile 29b in Trenton is adjacent to a small, late-nucleated kamacite lamella inside a plessite field (Fig. 8B). This kamacite nucleated about $80^{\circ}$ below the $\gamma /(\alpha+\gamma)$ boundary .

Data from Bristol are consistent with a cooling rate of $10^{\circ} / \mathrm{m} . \mathrm{y}$. and about $120^{\circ}$ supercooling before the Widmanstatten structure precipitated. However, none of the profiles had a high enough central $\mathrm{Ni}$ content to fall on the unindented segment of the curve, so only an upper limit of about $20^{\circ} / \mathrm{m} . \mathrm{y}$. can be placed on the cooling rate. The data are also consistent with $1 \% \mathrm{~m} . \mathrm{y}$. and $180^{\circ}$ supercooling, for example. But no other instance was found where Widmanstatten structure formed after this degree of supercooling (i.e., to $530^{\circ} \mathrm{C}$ ), so it seems unlikely that Bristol cooled at very much less than $10^{\circ} / \mathrm{m} . \mathrm{y}$.

The Henbury specimen studied turned out to be one of the pieces that Spencer (1933) found had been severely heated by impact with the earth (the Henbury irons are associated with a crater 160 meters in diameter). Re-heating has so badly degraded the Widmanstatten structure in the Henbury specimen studied that an estimate of its previous cooling history could not be made. 
Finally, profiles across the boundaries of scattered kamacite crystals in the Ni-rich ataxites were also used in an attempt to assess the thermal histories of these irons. Geometries of the structures profiled were totally unknown; double points entered in the Piñon and Monahans plots reflect the uncertainty this introduces. Extremely high cooling rates or else very great supercooling at lesser cooling rates are required to produce the diffusion structures these meteorites contain. Extreme supercooling is unlikely in the case of Piñon; a $16.5 \%$ alloy crosses the $\gamma /(\alpha+\gamma)$ boundary at $610^{\circ} \mathrm{C}$, and $\gamma$ phase appears to be very reluctant to transform at temperatures much lower than this. Of the instances of supercooling noted above, $540^{\circ} \mathrm{C}$ was the lowest temperature at which $\alpha$ precipitation occurred (Toluca 39a,b, Anoka $67 a$ ), only $70^{\circ}$ below Piñon's entry into the $\alpha+\gamma$ field. It is hard to avoid the conclusion that Piñon cooled relatively rapidly, probably at $1000^{\circ}$ $10,000^{\circ} / \mathrm{m} . \mathrm{y}$. Anders (1964) gives independent reasons for concluding that Ni-rich ataxites like Piñon cooled rapidly.

Cooling rate estimates, with uncertainties, are summarized in Fig. 22. No correlation between cooling rate and composition (Ni content) is apparent. However, the cooling rates do seem to correlate with the structural classes and Ga-Ge groups, where these are known, of the various octahedrites. Thus, the meteorites Grant, Trenton, Duchesne, Santa Apolonia, and probably Bristol cooled at approximately $10^{\circ} / \mathrm{m} . \mathrm{y}$. These are medium, fine and finest octahedrites, classes that form the Ga-Ge groups III 
and IV of Lovering, Nichiporuk, Chodos and Brown (1957). (These authors showed the iron meteorites fall into four discrete groups, according to their concentrations of $\mathrm{Ga}$ and $\mathrm{Ge}$, thus:

$\begin{array}{lcr}\text { Group } & \text { Ga }, \text { PPM } & \text { Ge, PPM } \\ \text { I } & 80-100 & 300-420 \\ \text { II } & 40-65 & 130-320 \\ \text { II I } & 8-24 & 15-80 \\ \text { IV } & 1-3 & <1-1\end{array}$

Four different metallurgical histories seem to be indicated, and it has been suggested that the groups were derived from four parent meteorite planets.)

The remaining five octahedrites cooled at approximately $1 \% \mathrm{~m} \cdot \mathrm{y}$. Of these, Cañon Diablo, Arispe and Odessa are coarse or coarsest octahedrites, classes which correlate with Ga-Ge groups I and II. Toluca is one of the few medium octahedrites that Lovering et al. found in Ga-Ge group II rather than III. Anoka is the only renegade of the set of octahedrites studied. It is a fine - finest octahedrite with high $\mathrm{Ni}$ content, therefore probably a member of Ga-Ge group III, yet it cooled slowly.

Excluding Anoka, then, the octahedrites studied could have been derived from as few as two parent meteorite planets. The core of one was relatively poor in $\mathrm{Ni}(5-10 \%)$, $\mathrm{rich}$ in $\mathrm{Ga}$ and $\mathrm{Ge}(\mathrm{Ga}>40 \mathrm{PPM}, \mathrm{Ge}>130 \mathrm{PPM})$, and cooled slow $1 \mathrm{y}$ $\left(0.5-2^{\circ} \mathrm{C} / \mathrm{m} . \mathrm{y}.\right)$. The core of the other was richer in $\mathrm{Ni}$ 
( 7 - $11 \%$ or more), poor in $\mathrm{Ga}$ and $\mathrm{Ge}(\mathrm{Ga}<24 \mathrm{PPM}, \mathrm{Ge}<80$ PPM), and cooled more rapidly $\left(5-20^{\circ} \mathrm{C} / \mathrm{m} . \mathrm{y}.\right)$. The octahedrites studied may equally well represent four planets, corresponding to the Ga-Ge groups, or even ten planets.

The differential equation for heat flow in spherical bodies was solved numerically by digital computer (Appendix I) to find the relationship between size of a planet and the rate at which its center cooled through the temperature range in which the Widmanstatten structure formed (Fig。23). We see that the range of cooling rates $0.5-2^{\circ} \mathrm{C} / \mathrm{m} . \mathrm{y}$. corresponds to a planet $130-260 \mathrm{~km}$ in radius. The range $5-20^{\circ} \mathrm{C} / \mathrm{m} \cdot \mathrm{y}$. requires a planet $50-90 \mathrm{~km}$ in radius. These are asteroidal dimensions. Three of the known asteroids -- Ceres, Pallas, and Vesta -must have cooled more slowly than $1^{\circ} \mathrm{C} / \mathrm{m} . \mathrm{y}$. At least six cooled more slowly than $10^{\circ} \mathrm{C} / \mathrm{m} . \mathrm{y}$. J. I. Goldstein (1964) has recently completed a thoroughgoing analysis of the thermal history of iron meteorites. Like the writer, he performed an electron probe - digital computer analysis of the Widmanstatten structure. Although his method and conclusions differ in detail from those presented here, his general conclusion is also that the iron meteorites formed in asteroidal bodies.

The potassium, uranium and hơrium content of chondritic or planetary matter is not adequate to heat such small planets to the melting point of iron, and so the idea has gained currency that they contained at the outset radionuclides of very short half-life, such as $\mathrm{Al}^{26}$, which in decaying provided a 
brief pulse of high temperature (Fish, Goles and Anders, 1960). Such a heat source is assumed to have provided the initial temperature of $1600^{\circ} \mathrm{C}$ which was used in the heat-flow calculations in this paper. The extremely high cooling rate deduced for Piñon is appropriate to a planet of only $5-12 \mathrm{~km}$ radius. So small a planet would have to contain a colossal amount of $\mathrm{Al}^{26}$ in order to melt. It seems more likely that an early collision between larger planets left Piñon to cool only a few kilometers beneath the fracture surface of one of the fragments.

It is interesting to note (Fig. 24) that a rough correlation exists between the cooling rates found and magnitude of the Agrell effect (i.e., maximum Ni content of kamacite minus $\mathrm{Ni}$ content of kamacite at the leading edge of M-profiles, averaged for each octahedrite). The sense of the relation is that slower cooling octahedrites show more pronounced Agrell effect. At slower cooling rates, diffusion in kamacite is active to a lower temperature. This supports the suggestion made in Section 3, that short-range diffusion in kamacite was still active after the $\alpha /(\alpha+\gamma)$ boundary reversed slope, so that the Agrell effect records the effort of kamacite to decrease its $\mathrm{Ni}$ content wherever $\alpha / \gamma$ phase boundaries were near at hand to serve as $\mathrm{Ni}$ sinks. 


\title{
5. PLESSITE
}

\begin{abstract}
Allen and Earley (1950) pointed out that annealed $\alpha_{2}$ alloys transform promptly into $\alpha+\gamma$. It seems probable that plessite formed in this manner: when supercooled meteoritic $\gamma$ phase crossed the $M_{S}$ curve and transformed to $\alpha_{2}$ phase, it was still in the $\alpha+\gamma$ field of stability (Fig. 3), and immediately began precipitating crystals of $\gamma$ phase. These grew to whatever size was consistent with the cooling rate and the diffusion coefficient of $\mathrm{Ni}$ in $\alpha_{2}$.
\end{abstract}

This is essentially the same mechanism proposed by Uhlig (1954), except that he invokes pressure-release to create the $\alpha_{2}$ phase. The cooling experiment described in section 1 shows that no such extraordinary event was needed; $\gamma$ phase is reluctant to transform to $\alpha+\gamma$, and one can hardly help getting $\alpha_{2}$ as the end product of cooling experiments on alloys of meteoritic composition.

The variability in coarseness of plessite is largely explained if it was derived from $\alpha_{2}$. The lower the $\mathrm{Ni}$ content of supercooled meteoritic $\gamma$ phase, the higher the temperature at which it crossed the $M_{S}$ line, and therefore the greater chance diffusion had to move Ni and allow crystals to grow. Thus, plessite grew coarsest at the centers of $\gamma$ regions, where $\mathrm{Ni}$ content was lowest. We can also understand why plessite areas generally do not resemble miniature Widmanstatten structures. Widmanstatten structures form by precipitation of $\alpha$ plates along $\{111\}$ planes in the host $\gamma$ phase; but if the host is $\alpha_{2}$ 
instead of $\gamma$, we have every reason to expect a completely different mode of precipitation.

An attempt was made to create plessite textures by heating $8 \% \mathrm{Ni}$ alloys (initially in the $\alpha_{2}$ state) at $663 \pm 14^{\circ} \mathrm{C}$ for varying lengths of time. Results are shown in Fig. 6D-F. No striking resemblance to meteoritic plessites (Fig. 10E-J) was obtained. The latter are highly variable in texture, and their crystallization is probably strongly influenced by phosphorus and carbon. Taenite grains in the annealed alloys grew to about $7 \mu$ radius in 7 days, about $12 \mu$ radius in 61 days.

It is interesting to test the idea that plessite evolved from supercooled $\gamma$ phase after it crossed the $M_{S}$ line, by calculating the size that $\gamma$ crystals growing in $\alpha_{2}$ phase could attain (under the assumption that this was limited only by the diffusion rate of $\mathrm{Ni}$ in $\alpha_{2}$ ), and comparing this with the dimensions of $\gamma$ crystals in real plessite. Unfortunately $\mathrm{D}\left(\mathrm{Ni}, \alpha_{2}\right)$ is not known. A crude comparison can be made by assuming $\mathrm{D}\left(\mathrm{Ni}, \alpha_{2}\right)=$ $\mathrm{D}(\mathrm{Ni}, \alpha)$. The quantity $\mathrm{D}(\mathrm{Ni}, \alpha) \mathrm{x}$ time predicts dimentions of 1.3 and $3.9 \mu$, respectively, for the $\gamma$ crystals grown during the annealing experiment described above, compared with dimensions of 7 and $12 \mu$ actually produced, so the approximation is not completely unrealistic.

Values of $\int \mathrm{D}(\mathrm{Ni}, \alpha) \mathrm{dt}$ for various $\mathrm{Ni}$ contents and cooling rates are given in Table 4 . In each case the integration was begun at the $M_{S}$ temperature for a $\gamma$ alloy of that composition. 
Armstrong's (1958) approximation to the above integral was used to calculate these diffusion distances. We see that plessite of micron or greater dimension is attainable in areas where bulk Ni content is less than $16-17 \%$; most plessite in octahedrites falls in this compositional range. However, Table 4 predicts that $\gamma$ phase with more than about $18 \%$ Ni should not have developed microscopically visible plessite. In meteorites, the cutoff seems to come at $21-22 \% \mathrm{Ni}$. The discrepency between these values probably reflects the difference between diffusion rates of $\mathrm{Ni}$ in $\alpha$ and $\alpha_{2}$ phases.

\section{ACKNOWLEDGMENTS}

I am indebted to J. I. Goldstein, E. Anders, R. Vogel, H. H. Uhlig, J. M. Short, and S. O. Agrell for discussions and correspondence at various times which contributed to my understanding of iron meteorites, such as it is. I am particularly grateful to Dr. Goldstein for allowing me to use his new determination of the diffusion coefficient of $\mathrm{Ni}$ in $\gamma$ phase, before it was published; the conclusions I have reached are dependent on this quantity. Meteorite specimens for this study were kindly provided by E. Anders, the U. S. National Museum, and the American Meteorite Museum. Metallographic assistance was rendered by Betty Nielsen. The research was supported by the National Aeronautics and Space Administration 
and the National Science Foundation. Much of the computer work - was done at the Smithsonian Astrophysical Observatory, Cambridge, Massachusetts, and supported by that organization. 


\section{BIBLIOGRAPHY}

Agre11, S. O., Long, J. V. P. and Ogilvie, R。 E。 (1963) Nickel content of kamacite near the interface with taenite in iron meteorites. Nature 198, 749-750。

Alekseeva, K. N. (1958) Physical properties of stony meteorites and their interpretation in the light of the hypothesis of the origin of meteorites (in Russian). Meteoritika $16,67-77$.

Alekseeva, K. N. (1960) New data on the physical properties of stony meteorites (in Russian)。 Meteoritika 18, 68-76.

Allan, D. W. and Jacobs, J.A. (1956) The melting of asteroids and the origin of meteorites. Geochim.et Cosmochim.Acta 9, 256-272.

Allen, N. P. and Earley, C.C。(1950) The transformations $\alpha \rightarrow \gamma$ and $\gamma \rightarrow \alpha$ in iron-rich binary iron-nickel alloys. J. Iron Steel Inst. (London) 166, 281-288.

Anders, E. (1964) Origin, age and composition of meteorites. Space Science Rev., in press.

Armstrong, H. L. (1958) On solid-state diffusion with a linearly varying temperature. Trans. A. I.M. E. 212, 450-451.

Bate, G. L., Huizenga, J. R. and Potratz, H. A. (1959) Thorium in stone meteorites by neutron activation analysis. Geochim. et Cosmochim. Acta 16, 88-100.

Benedicks, M. C. (1910) Synthèse du fer météorique. Nova Acta Regiae Soc. Sci. Upsaliensis (4) 2, No. 10, 26 pp. 
Bennek, H. and Schafmeister, P. (1931) Untersuchungen uber das Gebiet der $\delta-\gamma$ Umwandlung im System Fe-Ni. Arch. Eisenhuttenw. $5,123-125$.

Chladni, E. F. F. (1794) Über den Ursprung der von Pallas Gefunden und Anderer ihr Ähnlicher Eisenmassen und Über Einige Damit in Verbindung Stehende Naturerscheinungen. Riga: J. F. Hartknoch.

Derge, G. and Komme1, A。 R。 (1937) The structures of meteoric irons. Am. J. Sci. (5) 34, 203-214

Edwards, G. and Urey, H. C. (1955) Determination of alkali metals in meteorites by a distillation process. Geochim. et Cosmochim. Acta $\underline{7}, 154-168$ 。

Feller-Kniepmeyer, M. and Uhlig, H. H. (1961) Nickel analyses of metallic meteorites by the electronprobe microanalyzer. Geochim. et Cosmochim.Acta 21, 257-265.

Fish, R. A., Goles, G. G./ Anders, E. (1960) The Record in the Meteorites. III. On the development of meteorites in asteroidal bodies. Astrophys. J. 132, 243-258.

Goldberg, E., Uchiyama, A. and Brown, H. (1951) The distribution of nickel, cobalt, gallium, palladium and gold in iron meteorites. Geochim. et Cosmochim. Acta 2, 1-25.

Goldstein, J. I. (1964) The Growth of the Widmanstutten Pattern in Metallic Meteorites. Ph。 D. thesis, M. I. T. Dept. of Metallurgy.

Hamaguchi, H., Reed, G. W. and Turkevich, A. (1957) Uranium and barium in stone meteorites. Geochim. et Cosmochim. Acta $12,337-347$. 
Henderson, E. P. (1941) Corrections to published analyses of meteorites. Am. J. Sci. 239, 407-411.

Hirano, K., Cohen, M. and Averbach, B. L. (1961) Diffusion of nickel into iron. Acta Met. 9, 440-445.

Jones, F. W. and Pumphrey, W. I. (1949) Free energy and metastable states in the iron-nickel and iron-manganese systems. J. Iron Stee1 Inst. (London) 163, 121-131.

Kaufman, L. and Cohen, M. (1956) The martensitic transformation in the iron-nickel system. Trans. A. I. M. E. 206, 1393-1401.

Lovering, J. F., Nichiporuk, W., Chodos, A. and Brown, H. (1957) The distribution of gallium, germanium, cobalt, chromium, and copper in iron and stony-iron meteorites in relation to nickel content and structure. Geochim. et Cosmochim. Acta 11, 263-278.

MacEwan, J. R., MacEwan, J. V. and Yaffe, L. (1959) Diffusion of $\mathrm{Ni}^{63}$ in iron, cobalt, nickel, and two iron-nickel alloys. Can. J. Chem. 37, 1629-1636.

Maringer, R. E., Richard, N. A. and Austin, A. E. (1959) Microbeam analysis of Widmanstatten structure in meteoric iron. Trans. A. I. M. E. 215, 56-58.

Mehl, R. F. and Derge, G. (1937) Studies upon the Widmanstatten structure, VIII - The gamma-alpha transformation in ironnickel alloys. Trans. Am. Inst. Mining Met. Eng'rs, Iron Steel Div. 125, 482-500. 
Nininger, H. H. (1929) The Duchesne meteorite; an undescribed find from Duchesne County, Utah. J. Geol. 37, 83-87.

Nininger, H. H. (1931) An unusual iron meteorite from Mexico. Am. J. Sci. (5) 22, 360-363.

Nininger, H. H. (1939) The Monahans, Texas, meteorite. Pop. Astron. 47, 268-271

Osmond, F. and Cartaud, G. (1904) Sur les fers météoriques. Rev. Mét. 1, 69-79.

Owen, E. A. and Liu, Y. H. (1949) Further X-ray study of the equilibrium diagram of the iron-nickel system. J. Iron Steel Inst. (London) 163, 132-137.

Owen, E. A. and Sully, A. H. (1941) On the migration of atoms in iron-nickel alloys. Phil. Mag. (7) 31, 314-338.

Perry, S. H. (1944) The metallography of meteoric iron. U. S. Nat. Museum Bull. No. 184, 206 pp.

Ringwood, A. E. and Kaufman, L. (1962) The influence of high pressure on transformation equilibria in iron meteorites. Geochim. et Cosmochim. Acta 26, 999-1010.

Smith, J. L. (1869) A new meteoric iron - the Wisconsin meteorites, with some remarks on Widmanstatten figures. Am. J. Sci. (2) $47,271-272$.

Spencer, L. J. (1933) Meteoric iron and silica-glass from the meteorite craters of Henbury (Central Australia) and Wabar (Arabia) Mineral. Mag. 23, 387-404. 
Uhlig, H. H. (1954) Contribution of metallurgy to the origin of meteorites. Part I - Structure of metallic meteorites, their composition and the effect of pressure. Geochim. et Cosmochim. Acta 6, 282-301.

Urey, H. C. and Donn, B. (1956) Chemical heating for meteorites. Astrophys. J. 124, 307-310.

Voge1, R. (1925) Über die Struktur der Eisen-Nickel-Meteoriten. Z. anorg. u. allgem. Chemie 142, 193-228.

Voge1, R. (1951) Die Gefugeformen des Meteoreisens und ihre Erklarung auf Grund des Zustandsdiagrammes des Systems Eisen-Nickel-Phosphor. Neues Jahrb. Mineral. Abhandl. 83, $23-52$.

Vogel, R. (1957) Über Metabolite und ihre Kennzeichnung durch das Gefuge. Chem. Erde 19 (2), 147-169.

Wells, C. and Mehl, R. F. (1941) Rate of diffusion of nickel in gamma iron in low-carbon and high-carbon nickel.steels. Trans. Am. Inst. Mining Met. Eng'rs, Iron Steel Div. 145, $329-339$.

Wood, J. A. (1962) Meteorites: origin and distribution. Conference Report, NSF-NASA-VPI Conference on Physics of the Solar System and Reentry Dynamics (Blacksburg, Va., July 31 - Aug. 11, 1961).

Wood, J. A. (1963) Physics and chemistry of meteorites. Chap. 12 of The Moon, Meteorites and Comets (Vol. IV of The Solar System), ed. by Middlehurst and Kuiper. U. of Chicago Press. 
Yavnel', A. A., Borovski, I. B., Ilin, N. P. and Marchukova, I. D. (1958) Investigation of the composition of meteoritic iron phase by analysis of localized X-ray spectra (In Russian). Doklady Akad. Nauk S.S.S.R. 123, 256-258.

Young, J. (1926) The crystal structure of meteoric iron as determined by X-rays. Proc. Roy. Soc. (London) (A) 112, 630641 . 
Appendix I .

\section{PLANETARY HEAT-FLOW CALCULATIONS}

The differential equation for flow of heat in a homogeneous spherical solid body was solved numerically: by a digital computer program which yielded as output the temperature history of the center of the body. A 6 x 230. the computation, i.e., temperatures were calculated at the center of the planet and four points equally spaced between center and surface; and the calculations, which begin $4.6 \times 10^{9}$ years ago, proceed in two million year steps. Solutions are stable for planets of radius greater than about $47 \mathrm{~km}$. A larger number of computation points along the radius of the planet would have been desirable, but in order to maintain stability of solution for small planets the number of computations made by the machine and hence the cost of each temperature history would have had to increase as the cube of the number of radius intervals.

Where radioactive heat generation was assumed, this was based on chondritic levels of radionuclides. Initial abundances of $K, U$ and $T h$ which would yield the following measured presentday abundances were assumed:

$\mathrm{K}^{40} \ldots \ldots \ldots 1.01 \times 10^{-7} \mathrm{gm} / \mathrm{gm} \quad$ Edwards and Urey (1955)

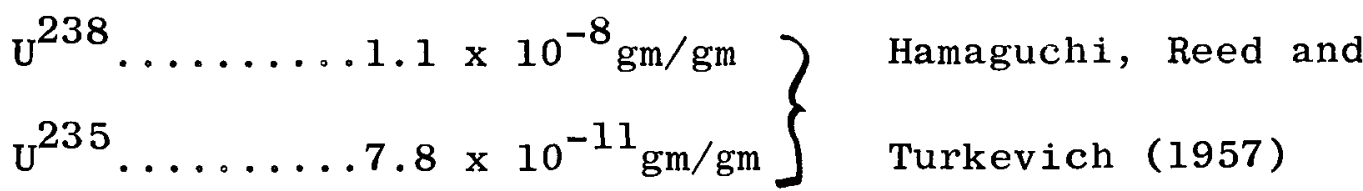

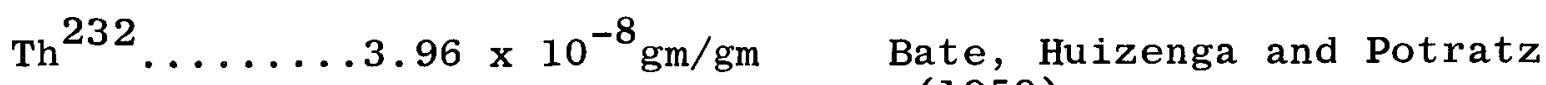


Other parameters assumed were as follows:

Density $=3.60 \mathrm{~cm} / \mathrm{cm}^{3}$.

Heat capacity $=0.198+\left(0.98 \times 10^{-4}\right) \mathrm{T}\left({ }^{\circ} \mathrm{K}\right) \mathrm{cal} / \mathrm{gm}{ }^{\circ} \mathrm{K}$,

based on the heat capacity of chondrites at room temperature (Alekseeva, 1958) and $\mathrm{dCp} / \mathrm{dt}$ for appropriate terrestrial rock types.

Thermal conductivity $=0.005 \mathrm{cal} / \mathrm{sec} \mathrm{cm}{ }^{\circ} \mathrm{K}$, the room temperature conductivity of chondrites (Alekseeva, 1960). Temperature coefficient not known.

Surface temperature of planet $=-103^{\circ} \mathrm{C}$, the mean black-body temperature of an object in the asteroid belt.

No allowance was made for partial melting or phase changes and their attendant heats of transition and changes in effective conductivity, nor for the appearance of radiative heat transfer at high temperatures.

In calculating curve A, Fig. 2, initial temperature was assumed to decrease linearly with radius in the planet, from $1600^{\circ} \mathrm{C}$ at the center to $-103^{\circ} \mathrm{C}$ at the surface. This configuration is the most favorable to Uhlig's requirement of central cooling that can reasonably be assumed. Higher initial temperatures in the outer reaches of the planet would have further inhibited heat loss from the center.

Calculation of the curves in Fig. 23 assumed chondritic levels of $\mathrm{K}, \mathrm{U}$ and $\mathrm{Th}$ in the planets, but this is unimportant. In the nearly straight portions of the curves, cooling rates are 
almost wholly dependent on thermal inertia of the planets. Only at the upper left ends of the curves, where they abrupily

increase in slope, does internal radioactive heat generation become important. 


\section{Appendix II.}

\section{A COMPUTER PROGRAM FOR NI DIFFUSION}

Fick's equation for diffusion of $\mathrm{Ni}$ in $\gamma \mathrm{Ni}-\mathrm{Fe}$ was approximated by the corresponding difference equation, and this was solved numerically for various cooling histories. Two considerations prevented the computation from being a straightforward one: the question of stability of solution, and the encroachment of growing $\alpha$ phase into the $\gamma$ field where diffusion calculations were being made.

If during the course of such a computation the quantity $\mathrm{Q}=\mathrm{D} \Delta \mathrm{t} /(\Delta \mathrm{x})^{2}$ exceeds a critical value, instability sets in $(D=N i$ diffusion coefficient, $\Delta t=t i m e$ interval between successive computations, $\Delta \mathrm{x}=$ distance between computation points on the diffusion profile). The problem is to choose $\Delta t$ and $\Delta x$ in such a way that $Q$ never exceeds the critical value.

A constant value for $\Delta t$ could not be used, since it was anticipated that a wide range of cooling rates would be tested, and any single value of $\Delta t$ would mean either too many computations and wasted machine time at low cooling rates, or too few computations and insufficiently detailed results at high cooling rates. Successive computations were therefore carried out at $1^{\circ} \mathrm{C}$ intervals, making $\Delta t=(\operatorname{cooling} \text { rate })^{-1}$.

Similarly, $\gamma$ regions of widely varying initial dimension were to be used, and these were expected to decrease in size during each run because of $\alpha$ encroachment. Therefore a fixed 
value of $\Delta x$ could not be used, since this would mean too many or too few points along the diffusion profile under differing circumstances.

D, of course, decreases drastically in value as temperature falls. Obviously, then, $Q$ could vary widely not only from one cooling run to another, but also during the course of each individual run.

Control was exercised over $Q$ by making available to the program a series of different mesh sizes -- i.e., the program could place 79 equally spaced computation points (=80 intervals) between an $\alpha / \gamma$ interface and the center of the developing Mprofile, or it could use $40,20,10,5$, or 2 intervals, or only 1. The value of $\Delta x$ depends on this number of mesh points assumed, and $Q$ depends on $\Delta x$, so the program was able to maintain stability by choosing at each computational step a sufficiently small number of mesh points. (The program used the maximum number of mesh points consistent with stability.) In the event that $Q$ was too large for stability even if only 1 interval was assumed, the program abandoned use of the diffusion equation and simply set central $\mathrm{Ni}$ concentration equal to $\mathrm{Ni}$ concentration at the $\alpha / \gamma$ interface $(D=\infty)$.

As temperature decreased in each computer run, D decreased and the mesh became correspondingly finer. In a typical run, beginning at $960^{\circ} \mathrm{C}$, the program was forced to assume $\mathrm{D}=\infty$ until temperature dropped to $903^{\circ}$. There it began to solve the 
diffusion equation for only one mesh interval. By $848^{\circ}$, D

- had decreased sufficiently to allow the interval to divide into two. At $798^{\circ}$ these became 5 , at $766^{\circ} 10$, at $739^{\circ} 20$, at $715^{\circ} 40$, and from $701^{\circ}$ until the program terminated, 80 intervals were used.

The program's way of taking into account encroachment of growing $\alpha$ phase on the $\gamma$ region is best explained by an example. Fig. 25 shows what happens during each step in the computation (exaggerated).

A: This is the diffusion profile arrived at by the previous step. It is divided into five intervals, the maximum number consistent with stability.

B: This step is carried out at a temperature $1^{\circ}$ lower than the last step. $D(\mathrm{Ni}, \gamma)$ will therefore be smaller. The equilibrium concentration of $\mathrm{Ni}$ in $\gamma$ phase will be greater. The latter value is calculated from an algebraic equation fitted to the $\gamma /(\alpha+\gamma)$ boundary of Owen and Liu (1949). The lefthand mesh point takes on this new value. This point represents $\mathrm{Ni}$ concentration at the $\alpha / \gamma$ interface, and is assumed to equal the equilibrium concentration of $\mathrm{Ni}$ in $\gamma$ phase at all times.

C: The difference equation for flow of $\mathrm{Ni}$ is now solved at the five interior mesh points, using the new lower value of $\mathrm{D}(\mathrm{Ni}, \gamma)$. Ni concentrations increase at these points. 
D: The total amount of $\mathrm{Ni}$ in $\gamma$ phase is assessed by cal- culating the area under the profile in C. Equilibrium Ni content of $\alpha$ phase is calculated from an algebraic equation fitted to one of the $\alpha /(\alpha+\gamma)$ boundaries in Fig. 18. The total amount of $\mathrm{Ni}$ in $\alpha$ phase is computed, under the assumption that the whole $\alpha$ region (dimension $=$ initial size of $\gamma$ region, when $\alpha$ nucleation began, minus present size of $\gamma$ region) contains the equilibrium concentration of $\mathrm{Ni}$. $\mathrm{Ni}$ in $\gamma$ plus $\mathrm{Ni}$ in $\alpha$ is compared with bulk $\mathrm{Ni}$ content that was originally assumed for the system, and a surplus found, since both $\alpha$ and $\gamma$ phases have increased their concentrations of $\mathrm{Ni}$ during this step. The surplus is balanced off by shifting the $\alpha / \gamma$ interface an appropriate distance to the right ( $\alpha$ encroachment). The new position of the interface is calculated; in general it falls between two of the mesh points.

E: A new, smaller value of $\Delta x$ is now chosen, to restore the truncated profile to a reference system of six equally spaced mesh points (five intervals). Ni concentration values for the new points are based on linear interpolations between the old ones.

$F: Q$ is reassessed. $D$ and $\Delta x$ are smaller than they were when this was last done. This time it is found that stable solutions can be obtained with a ten-interval mesh. New mesh points are inserted, their $\mathrm{Ni}$ concentrations based on linear interpolations between the original six points. 
Table 1 .

Classification of Octahedrites

\begin{tabular}{l|c|c|c|c} 
& $\begin{array}{l}\text { Rose-Tschermak- } \\
\text { Brezina symbol }\end{array}$ & $\begin{array}{l}\text { Thickness of } \\
\text { kamacite plates, } \\
\mathrm{mm}\end{array}$ & $\begin{array}{l}\text { Bulk Ni } \\
\text { content, } \\
\text { wt. pct. }\end{array}$ & $\begin{array}{c}\text { Relative } \\
\text { abundance } \\
\text { (finds }+ \\
\text { falls) }\end{array}$ \\
\hline Coarsest & Ogg & $>2.5$ & $6-7$ & $6 \%$ \\
Coarse & Og & $1.2-2.5$ & $6.5-7.5$ & $23 \%$ \\
Medium & Om & $0.5-1.2$ & $6.5-10$ & $49 \%$ \\
Fine & Of & $0.2-0.5$ & $7.5-10.5$ & $16 \%$ \\
Finest & Off & $<0.2$ & $8-15$ & $6 \%$
\end{tabular}


Table 2 .

\begin{tabular}{|c|c|c|c|}
\hline Meteorites studied & Classification & $\begin{array}{c}\text { Nickel } \\
\text { content, } \\
\text { Wt. } \%\end{array}$ & $\begin{array}{l}\mathrm{Ga}-\mathrm{Ge} \\
\text { group }\end{array}$ \\
\hline Arispe & Ogg & $6.77^{\mathrm{b}}$ & I I \\
\hline Cañon Diablo & $\mathrm{Og}$ & $7.17^{\mathrm{b}}$ & (I) \\
\hline Odessa & $\mathrm{Og}$ & $7.55^{\mathrm{b}}$ & - \\
\hline Trenton & $\mathrm{Om}$ & $7.91^{\mathrm{c}}$ & - \\
\hline Santa Apolonia & $\mathrm{Om}$ & $7.83^{b}$ & - \\
\hline Henbury & $\mathrm{Om}$ & $7.70^{b}$ & II \\
\hline Toluca & $\mathrm{Om}$ & $8.31^{b}$ & I I \\
\hline Bristol & Off & $8.15^{b}$ & IV \\
\hline Duchesne & of & $9.20^{\mathrm{d}}$ & IV \\
\hline Grant & of & $9.35^{\mathrm{e}}$ & - \\
\hline Anoka & Of-Off & $11.49^{c}$ & - \\
\hline Monahans & & $10.88^{f}$ & - \\
\hline Piñon & $\left\{\begin{array}{l}\mathrm{Ni}-\mathrm{rich} \\
\text { ataxites }\end{array}\right.$ & $16.58^{b}$ & IV \\
\hline Tlacatopec & & $16.23^{\mathrm{g}}$ & IV \\
\hline
\end{tabular}

a. Lovering, Nichiporuk, Chodos and Brown (1957)

b. Goldberg, Uchiyama and Brown (1951)

c. Gravimetric chemical analyses by the author, using the dimethylglyoxine method. Smith (1869) reported $7.20 \%$ $\bar{N} \mathbf{i}$ in Trenton.

d. Nininger (1929)

e. Henderson (1941)

f. Nininger (1939)

g. Nininger (1931) 
Table 3 .

Approximate diffusion distances, $(D t)^{1 / 2}$, in kamacite

\begin{tabular}{l|r}
$\mathrm{T},{ }^{\circ} \mathrm{C}$ & distance, $\mu$ \\
\hline 600 & 13000 \\
580 & 9000 \\
560 & 6000 \\
540 & 4000 \\
520 & 2700 \\
500 & 1700 \\
480 & 1000 \\
460 & 600 \\
440 & 340 \\
420 & 160 \\
400 & 80
\end{tabular}


Table 4.

Diffusion distances for Nickel in $\alpha$ phase

\begin{tabular}{c|c|c|c}
\multirow{2}{*}{$\begin{array}{c}\text { Wt. } \% \\
\text { Ni in } \\
\text { alloy }\end{array}$} & $\begin{array}{c}\mathrm{M}_{\mathrm{S}} \\
{ }^{\circ} \mathrm{C}\end{array}$ & \multicolumn{2}{|c}{$\int \mathrm{Ddt}, \mathrm{microns}$} \\
\cline { 3 - 4 } 10 & 520 & 2100 & 660 \\
12 & 440 & 260 & 82 \\
14 & 370 & 29 & 9.1 \\
16 & 320 & 3.9 & 1.2 \\
18 & 260 & 0.21 & 0.068 \\
20 & 210 & 0.010 & 0.0033 \\
22 & 160 & 0.0004 & 0.0001
\end{tabular}




\section{Figure Captions}

Fig. 1. Phase diagram for part of the binary system Fe-Ni, at one atmosphere pressure, together with idealized Ni profiles which might develop in an $8 \% \mathrm{Ni}$ alloy as it cooled through the $\alpha+\gamma$ field. High temperature portion of phase diagram from Bennek and Schafmeister (1931); low temperature portion from Owen and Liu (1949).

Fig. 2. Calculated thermal histories of the center of a stony planet, radius $=1290 \mathrm{~km}$. A, no radioactive heat sources, initial temperature of $1600^{\circ} \mathrm{C} . \mathrm{B}, \mathrm{C}$, same content of $\mathrm{K}$, $\mathrm{U}$ and $\mathrm{Th}$ as chondritic meteorites; high and low initial temperatures. Hatched band, temperature of formation of Widmanstatten structure according to Uhlig (1954).

Fig. 3. Fe-Ni phase diagram, with $\alpha_{2}$ transformation curves. Heavy solid lines, Owen and Liu (1949), experimental. Dashed lines, Kaufman and Cohen (1956), calculated. $M_{S}$ and $A_{S}$, Kaufman and Cohen (1956), experimental.

Fig. 4. Counting rates of $\mathrm{Ni}_{\alpha}$ radiation emitted by five artificial Fe-Ni alloys.

Fig. 5. Deleted.

Fig. 6. A, Trenton octahedrite, macrophotograph of polished and etched surface, showing Widmanstatten structure. B-J, photomicrographs of structures in artificial Fe-Ni alloys, surfaces polished and etched with picral, viewed by reflected light. Black spots are iron oxide inclusions. Scale bars, $100 \mu$. Arrows 
are traces of microprobe profiles appearing in Fig. 11, and show - direction of movement of beam. B, $18 \% \mathrm{Ni}$ alloy and $\mathrm{C}, 8 \% \mathrm{Ni}$ alloy cooled at $-6^{\circ} \mathrm{C} /$ day from $800^{\circ} \mathrm{C}$ to room temperature. Both consist of $\alpha_{2}$ phase. The $18 \%$ alloy shows a bogus Widmanstatten structure. $\mathrm{D}$ and $\mathrm{E}, 8 \% \mathrm{Ni}$ alloys annealed at $663^{\circ} \mathrm{C}$ for 7 (D) and 61 (E) days, showing growth of $\gamma$ crystals. F, $8 \% \mathrm{Ni}-$ 61 day annealed alloy at higher magnification. Large clear areas are $\gamma$ phase. $\mathrm{G}, 8 \% \mathrm{Ni}, 0.2 \% \mathrm{P}-61$ day alloy.

Fig. 7. Figs. 7 - 10 are photomicrographs of structures in iron meteorites, surfaces polished and etched with picral, viewed by reflected 1ight. Numbered arrows are microprobe scans appearing in Figs. 12 - 16. T-shaped symbols show angle at which planar

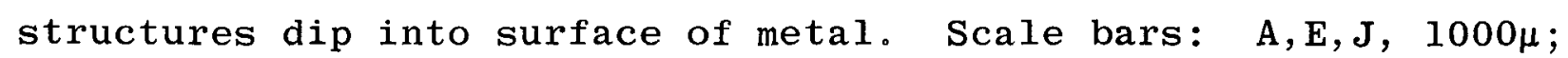

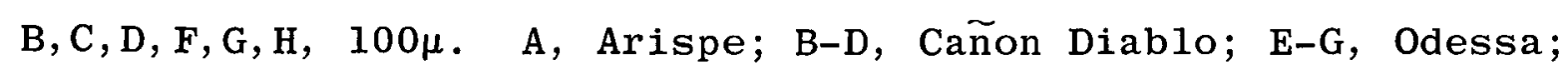
J, Trenton; octahedrites. Dark areas are plessite, surrounding light areas are kamacite. Taenite appears as thin light-colored bands in parallel array or separating plessite from kamacite.

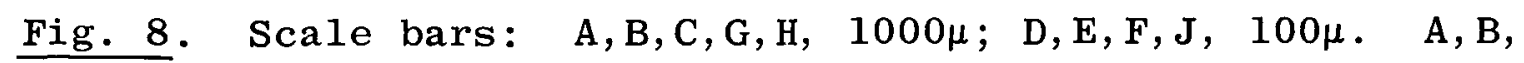
Trenton; C,D, Santa Apolonia; E, Henbury; F-H, Toluca; J, Bristol; octahedrites. Henbury has suffered reheating on earth impact; note granulation in taenite-plessite area and appearance of small taenite needles in kamacite.

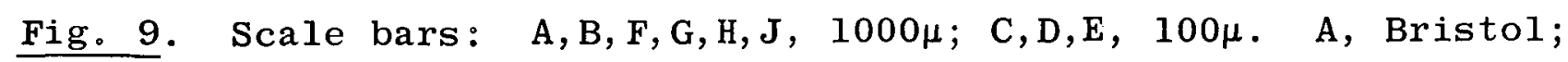
B-D, Duchesne; E-H, Grant; J, Anoka; octahedrites. 
Fig. 10. Scale bars: A, B, $1000 \mu ; \mathrm{C}, \mathrm{D}, \mathrm{J}, 100 \mu ; \mathrm{E}, \mathrm{F}, \mathrm{G}, \mathrm{H}, 50 \mu . \quad$ A, Anoka, octahedrite; B,C, Monahans, and D, E, Piñon, Ni-rich ataxites; F-G, plessite textures at high magnification, in F, Tlacatopec, Ni-rich ataxite; G, Odessa, octahedrite; H, Toluca, octahedrite; J, Grant, octahedrite, showing plessite, taenite (clear), and kamacite (top of photograph).

Fig. 11. Figs. 11-16 contain electron microprobe profiles taken in artificial alloys and iron meteorites, numbered in correspondence with traces shown in Figs. 6-10. In all cases beam moved from right to left (arrows). 1,2, profiles in $18 \% \mathrm{Ni}$ and $8 \% \mathrm{Ni}$ cooled alloys, showing homogeneity. 3-5, profiles in $8 \% \mathrm{Ni}$ annealed alloy; $6,7,8 \% \mathrm{Ni}-0.2 \% \mathrm{P}$ annealed alloy.

Fig. 12. Profiles 8-10, Arispe; 11-17, Cañon Diablo; 18-26, Odessa.

Fig. 13. Profiles 27-29, Trenton; 30-32, Santa Apolonia; 33, Henbury; 34-41, Toluca.

Fig. 14. Profiles 42,43, Toluca; 44-51, Bristol; 52-54, Duchesne; 55-59, Grant.

Fig. 15. Profiles 60-65, Grant; 66,67, Anoka.

Fig. 16. Profiles 68,69, Monahans; 70-73, Piñon.

Fig. 17. A: Typical M-profile, measured in Odessa. B: Unsuccessful attempts to match $A$ with computed profiles, using $\alpha /(\alpha+\gamma)$ boundary of Owen and Liu (1949) and assuming various cooling rates. C: More successful attempts to match A, using the some- 
what different $\alpha /(\alpha+\gamma)$ boundary shown in Fig. 18. D: Detailed match between measured and computed profiles (latter plotted as black dots), for cooling rate of $1.5^{\circ} \mathrm{C} / \mathrm{million}$ years.

Fig. 18. $\alpha /(\alpha+\gamma)$ boundary of Owen and Liu (1949), and boundary that appears to have controlled formation of octahedrites. Hatched areas: $\alpha$ phase ( \pm uncertainty) created in annealing experiments.

Fig. 19. Typical relationship between dimension of computed Mprofile and $\mathrm{Ni}$ content at center. Dashed lines show effects produced by varying parameters. A: Decrease in bulk Ni content of system. B: Increase in cooling rate. C: Decrease in temperature of nucleation.

Figs. 20 and 21. Comparisons between computed and measured half-width - central $\mathrm{Ni}$ content relationships in M-profiles. Computed relationships plotted as lines; solid lines represent the case in which no supercooling was assumed; these are labeled according to cooling rate assumed. Where various degrees of supercooling were assumed, the deviations these caused from the no-supercooling case are shown as dashed lines. The bulk Ni content assumed in computing each relationship is shown at lower left : Measured meteoritic half-width - central Ni content relationships are entered as points, numbered in correspondence with profiles in Figs. 12-16. White points represent profiles abutted by late-crystallized kamacite; supercooling has exerted some influence on these. Black points represent profiles bounded 
by relatively early-formed kamacite. Supercooling may or may not have preceded crystallization of the latter.

Fig. 22. Cooling rates of octahedrites studied, plotted against composition.

Fig. 23. Cooling rate (at $\mathrm{T}=500^{\circ} \mathrm{C}$ ) at centers of planets of chondritic composition, as a function of size. Curves for two different assumed initial temperature distributions are given. Planets of radius greater than about $420 \mathrm{~km}$ would not cool to $500^{\circ} \mathrm{C}$ during the age of the solar system.

Fig. 24. Relationship between cooling rate and average magnitude of Agrell effect (defined as \% $\mathrm{Ni}$ at centers of kamacite plates minus \% $\mathrm{Ni}$ in kamacite at kamacite/taenite interface) in octahedrites studied. 


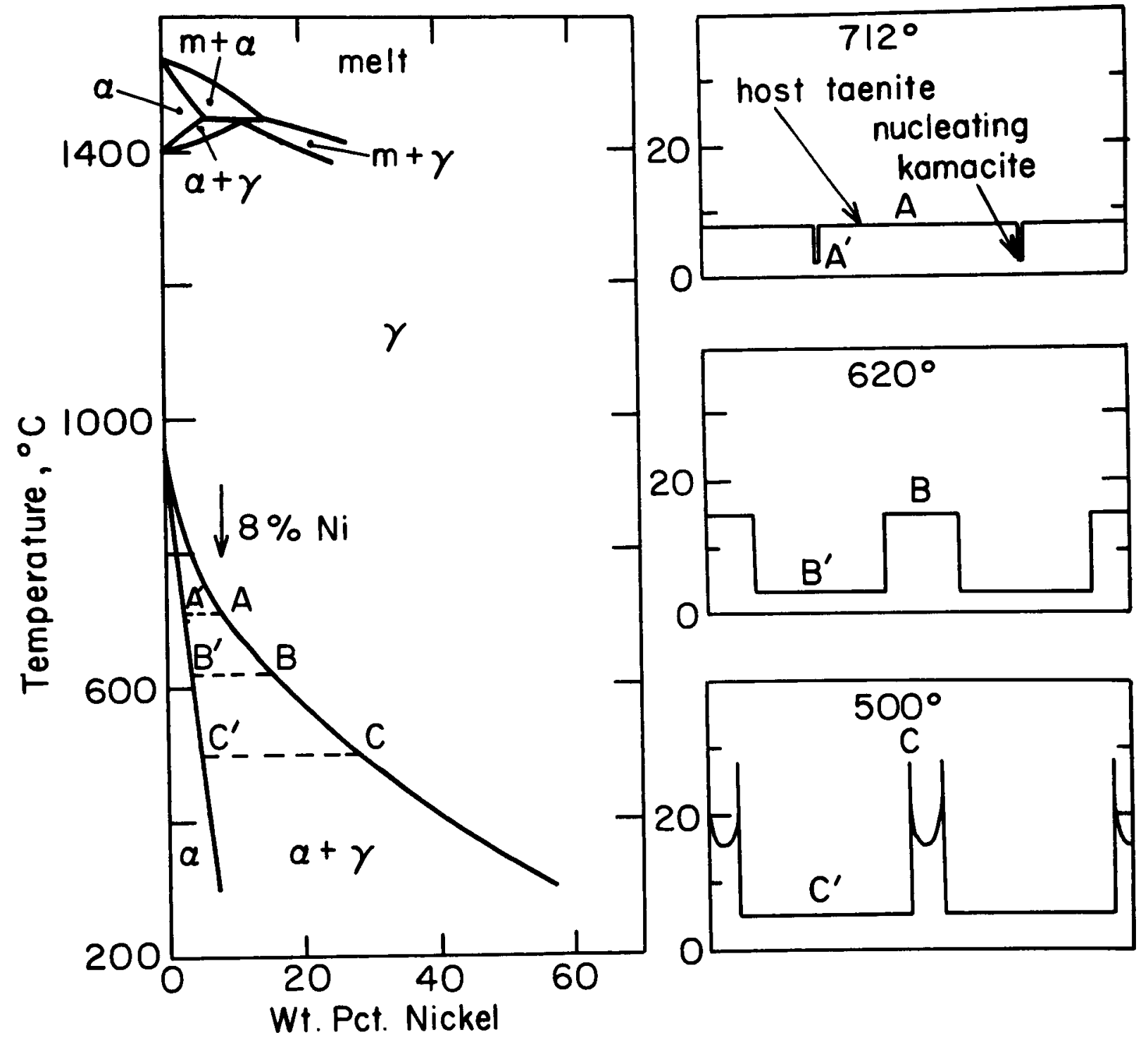

Fig. ! 


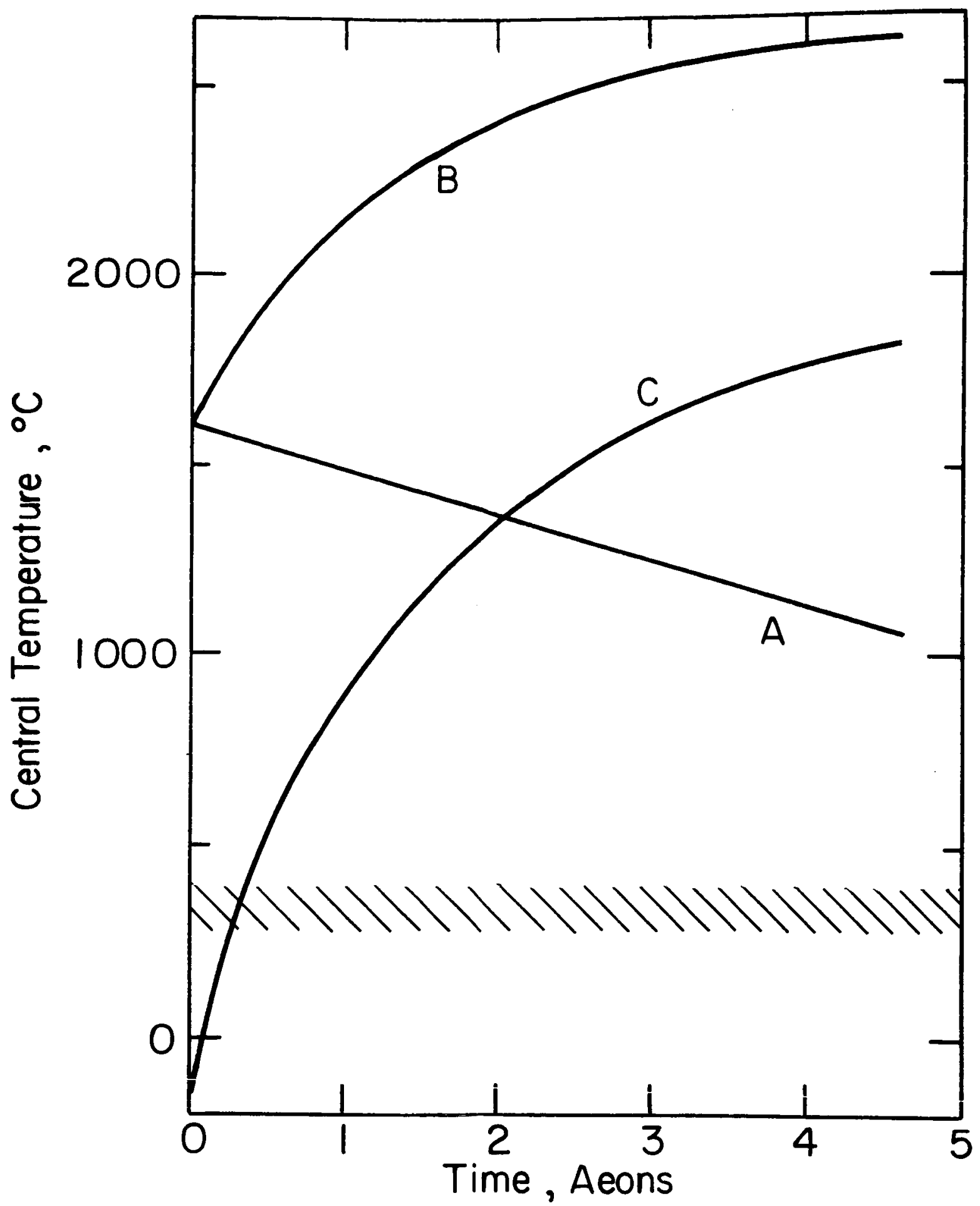

Fig. 2 


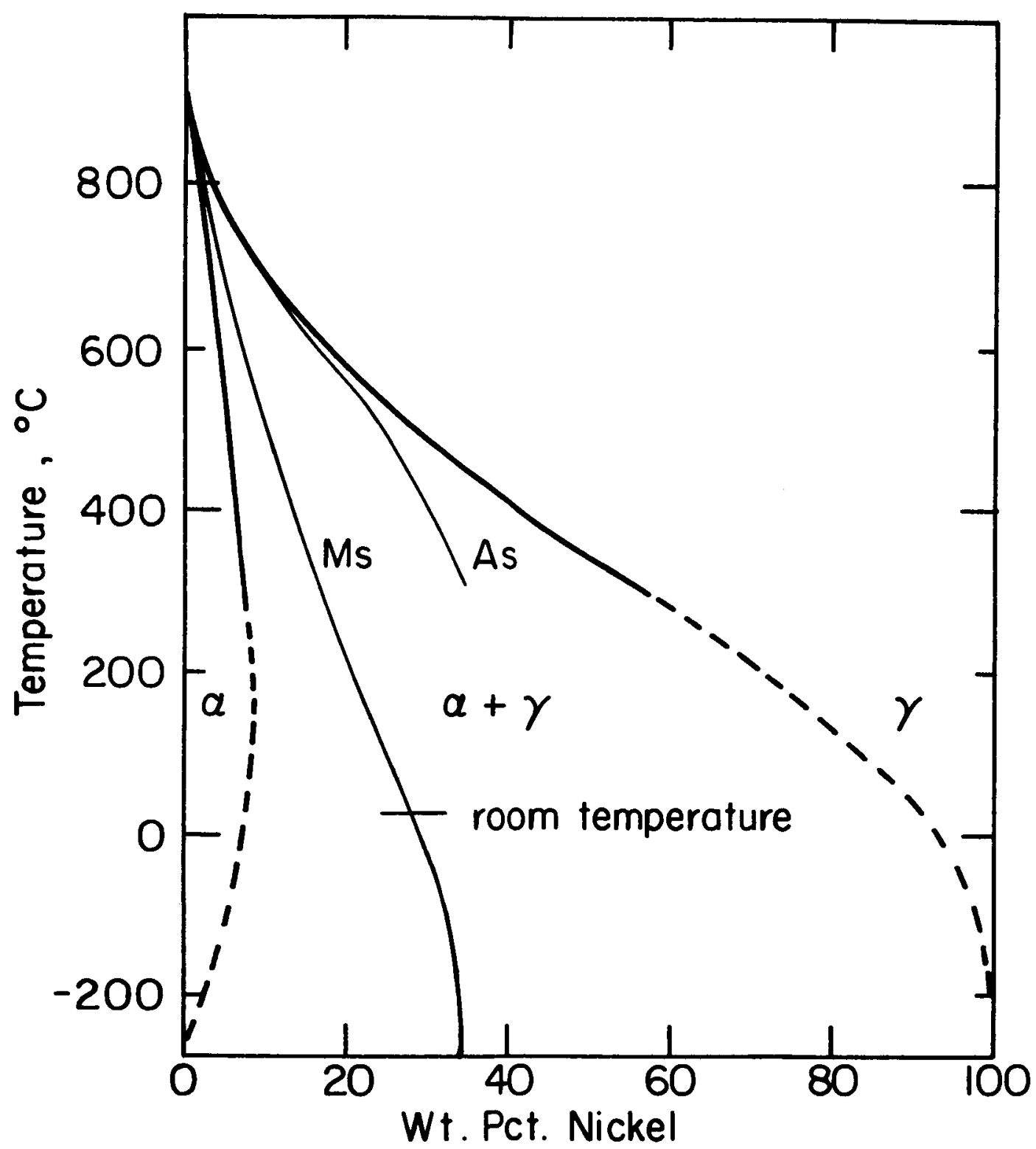

Fig. 3 


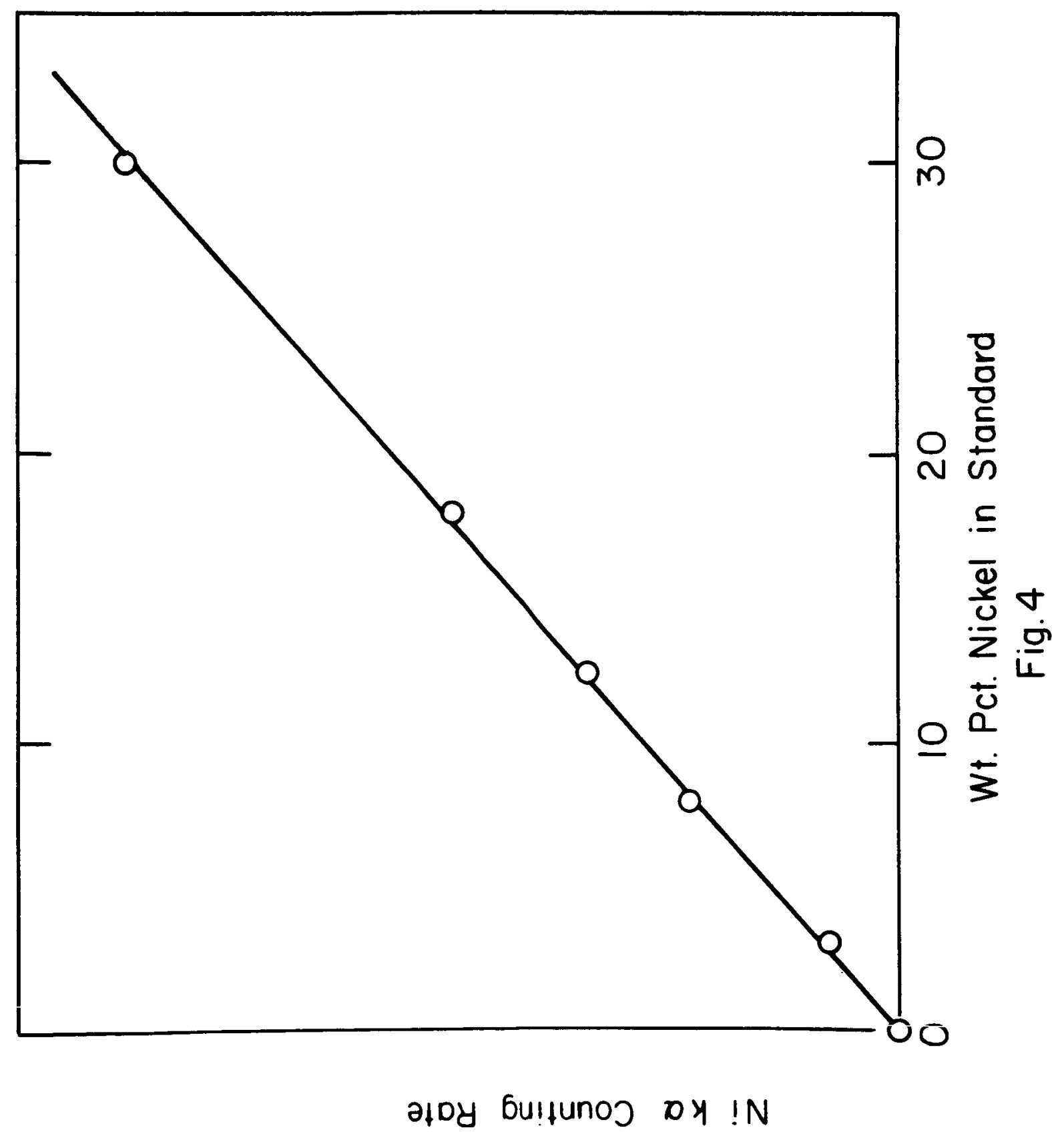




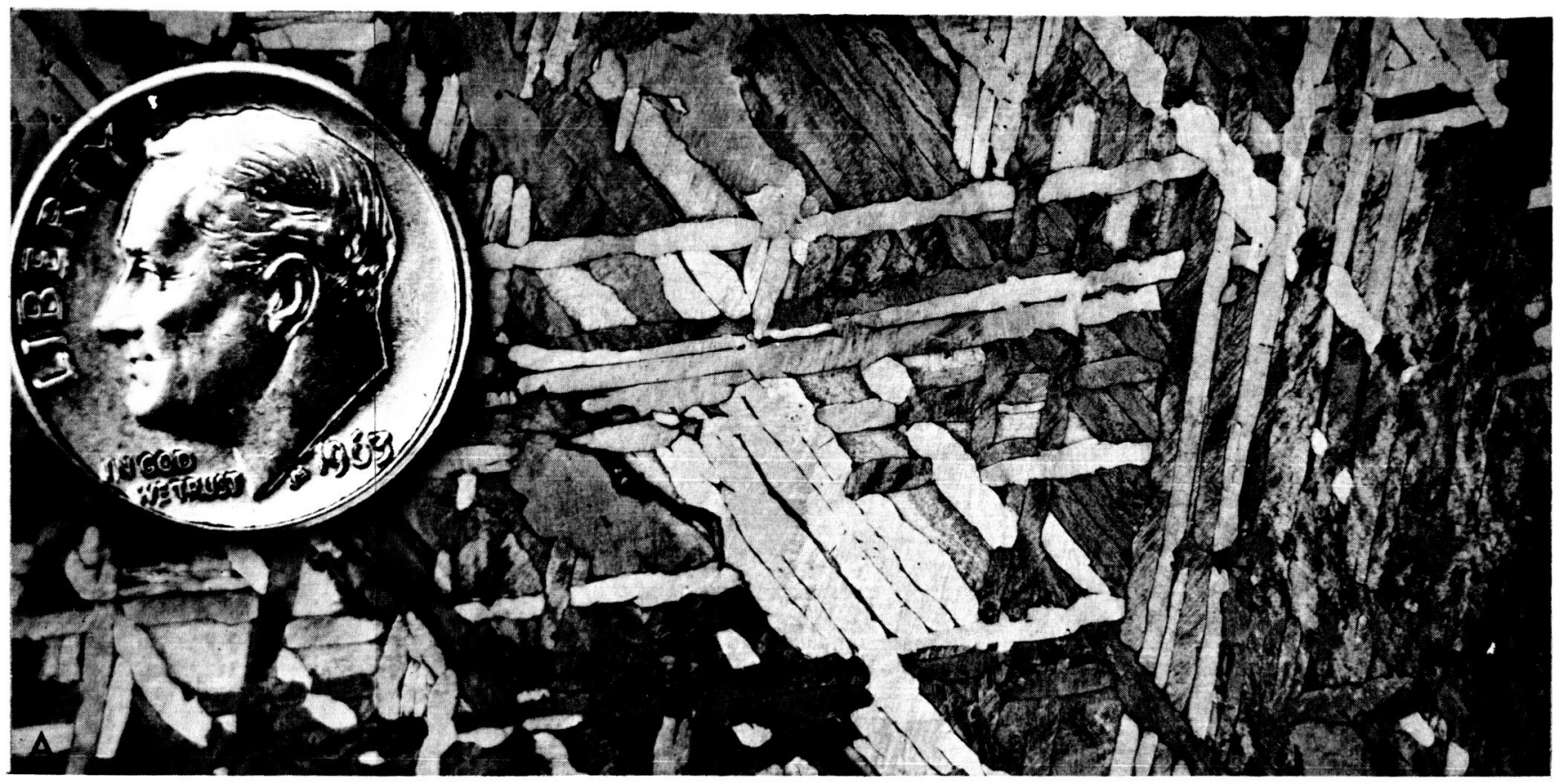

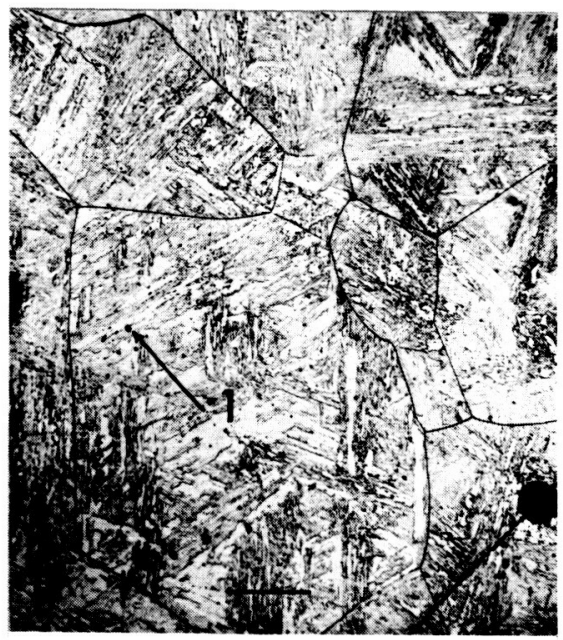

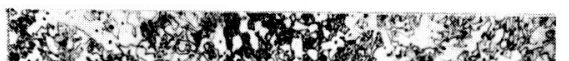

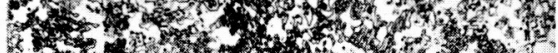

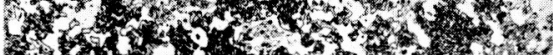

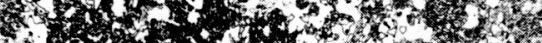

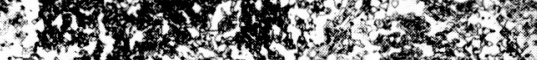

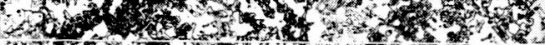

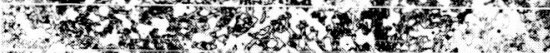

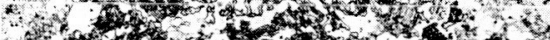
1.

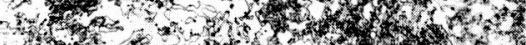

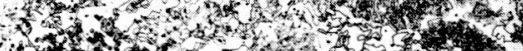

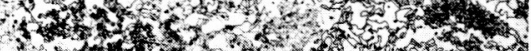

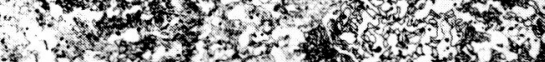
4 b.

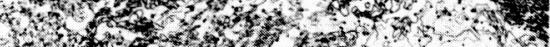

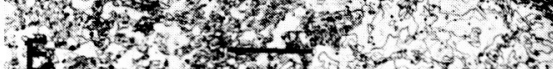
$28 \%$, w

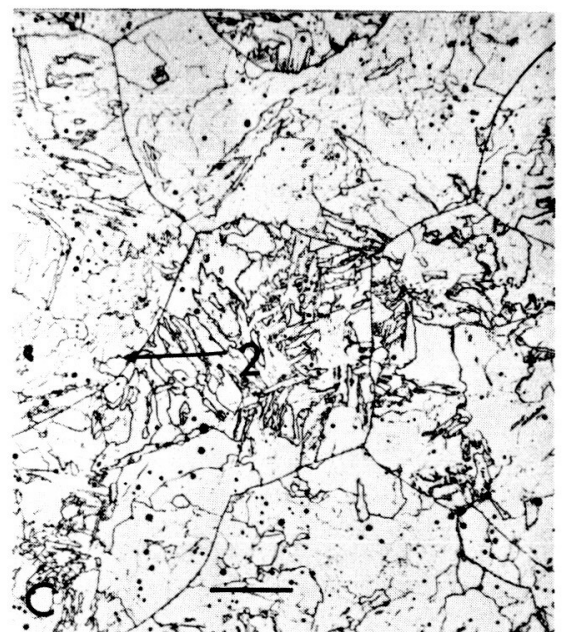

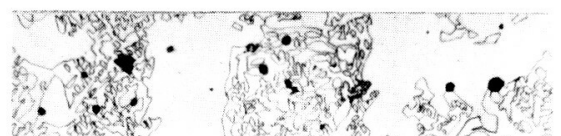

$\int_{5}^{5} \cdot 0^{2}$

- to 3. ${ }^{2}$. 104 or Q3 3 .

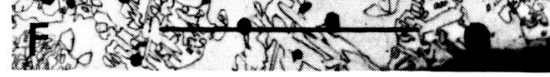
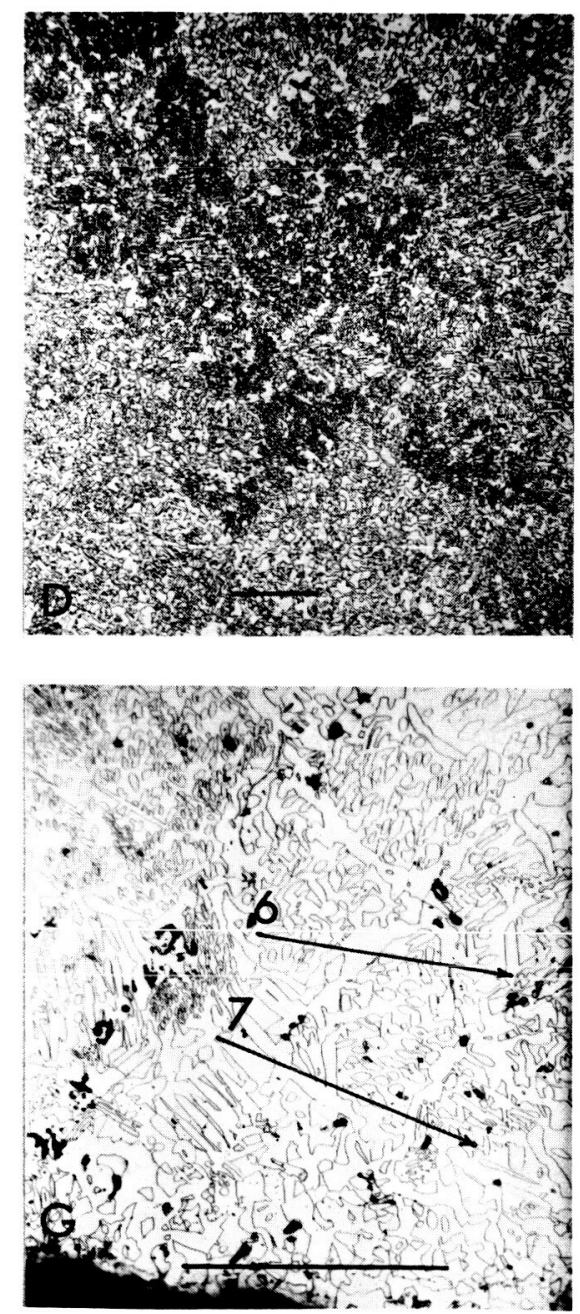

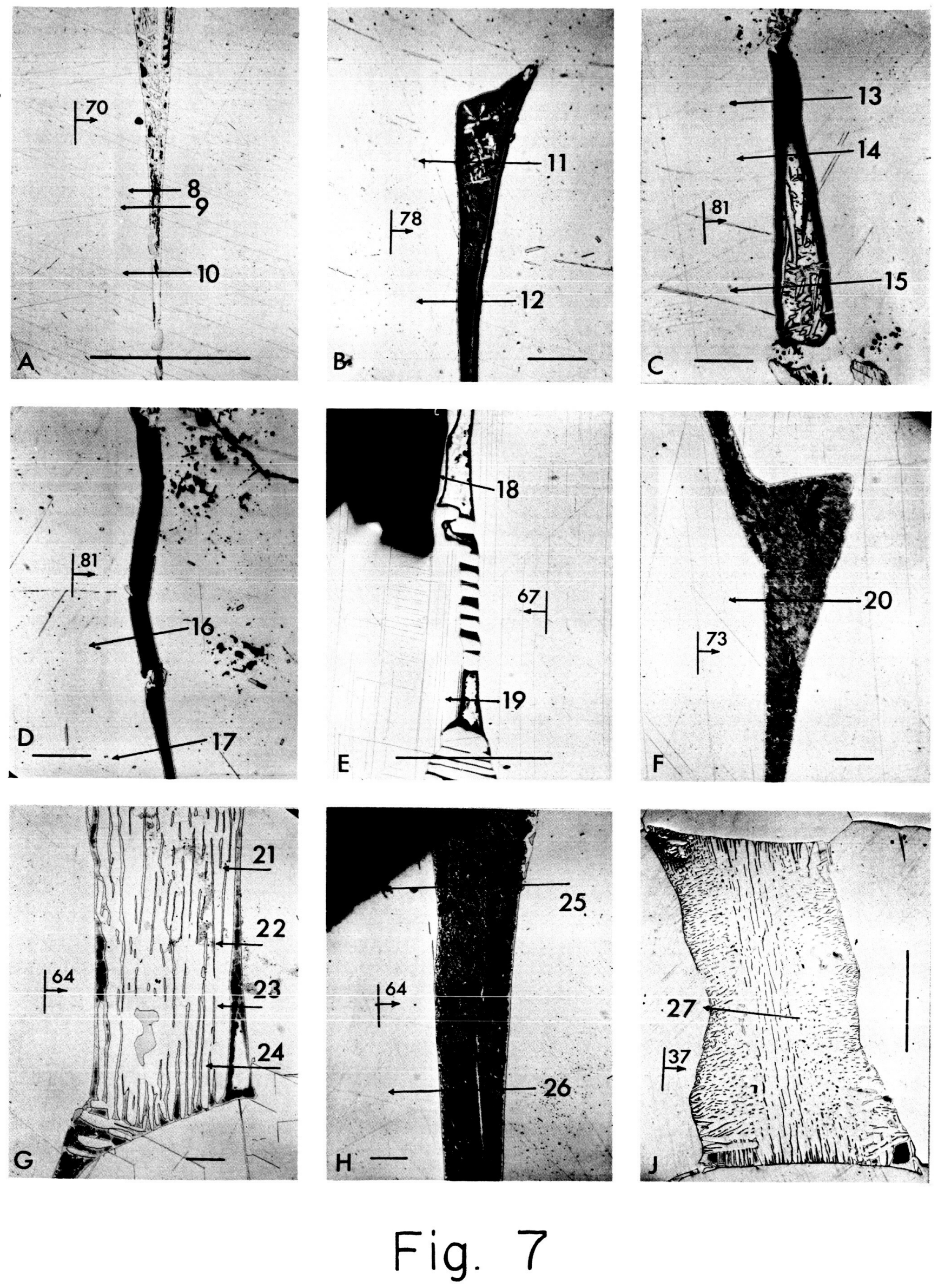

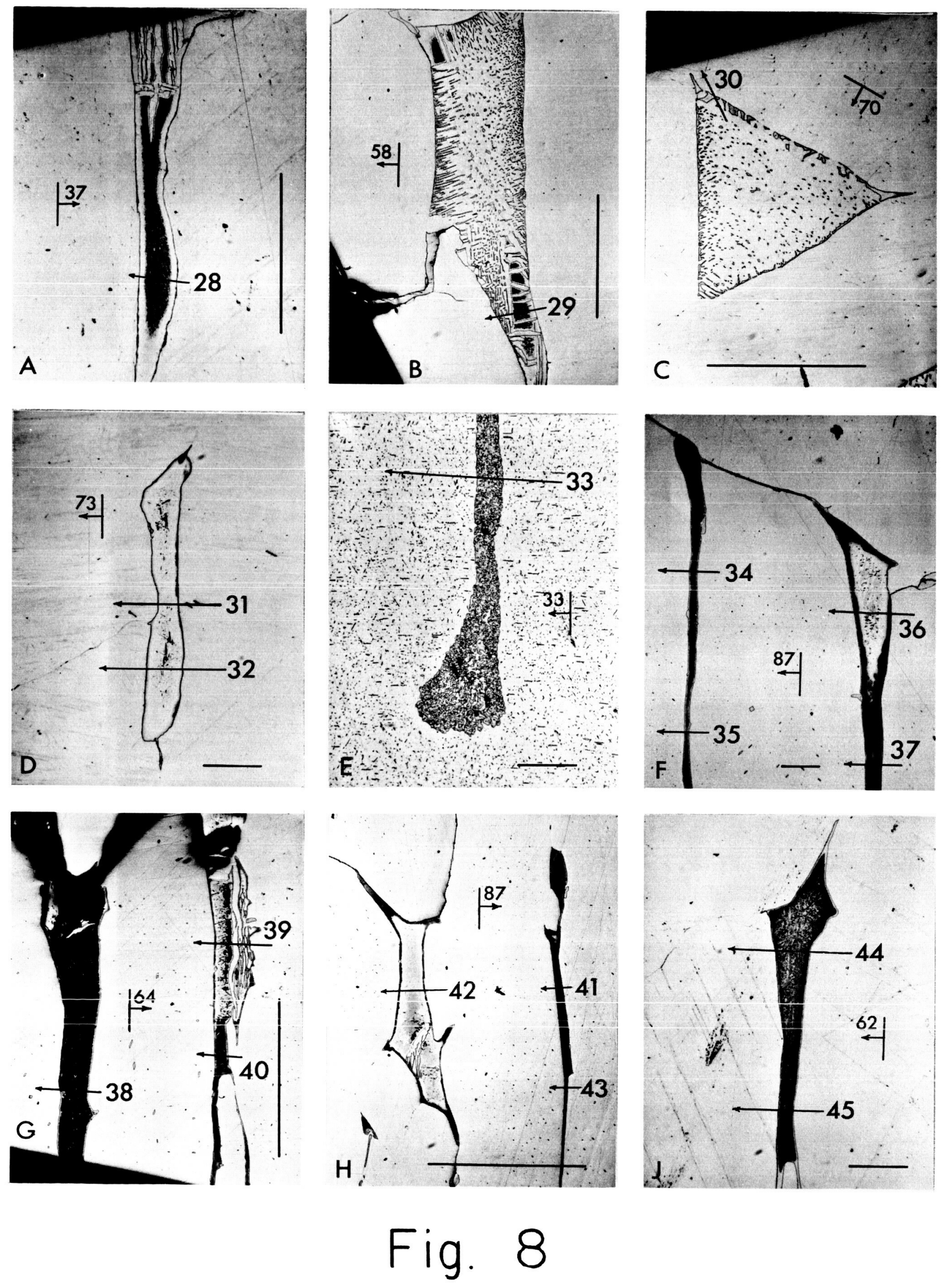

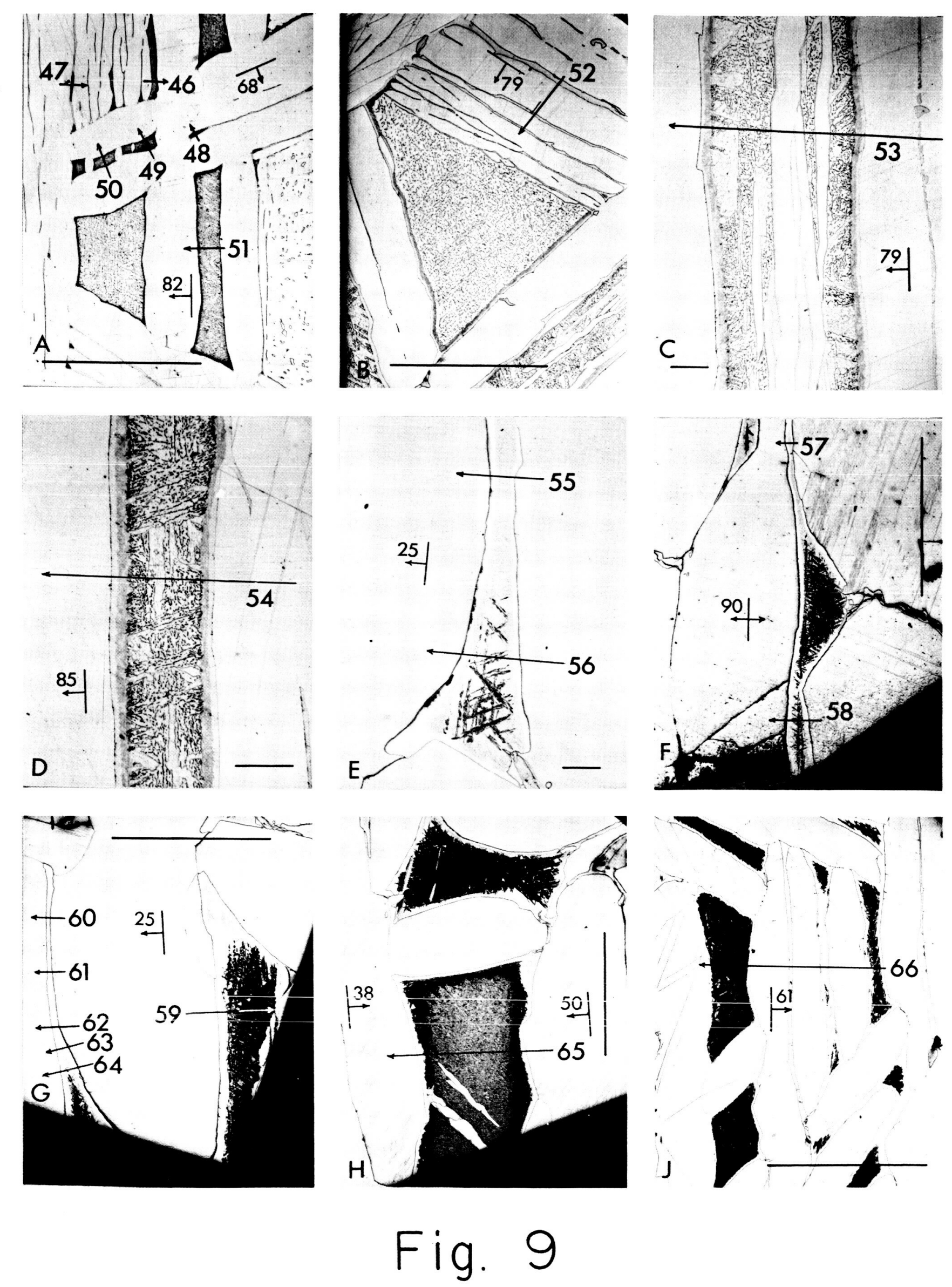

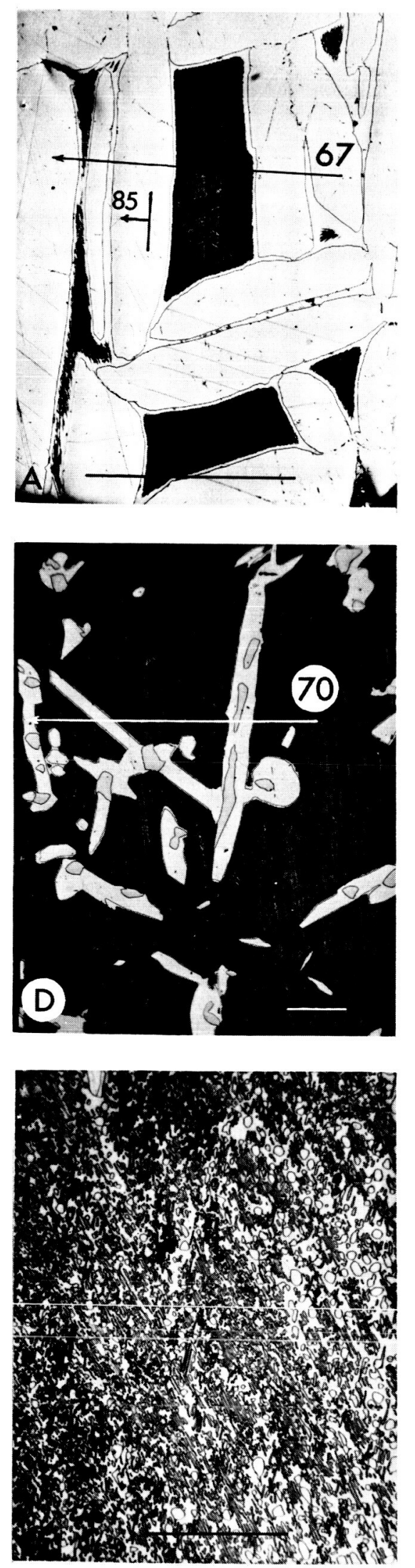
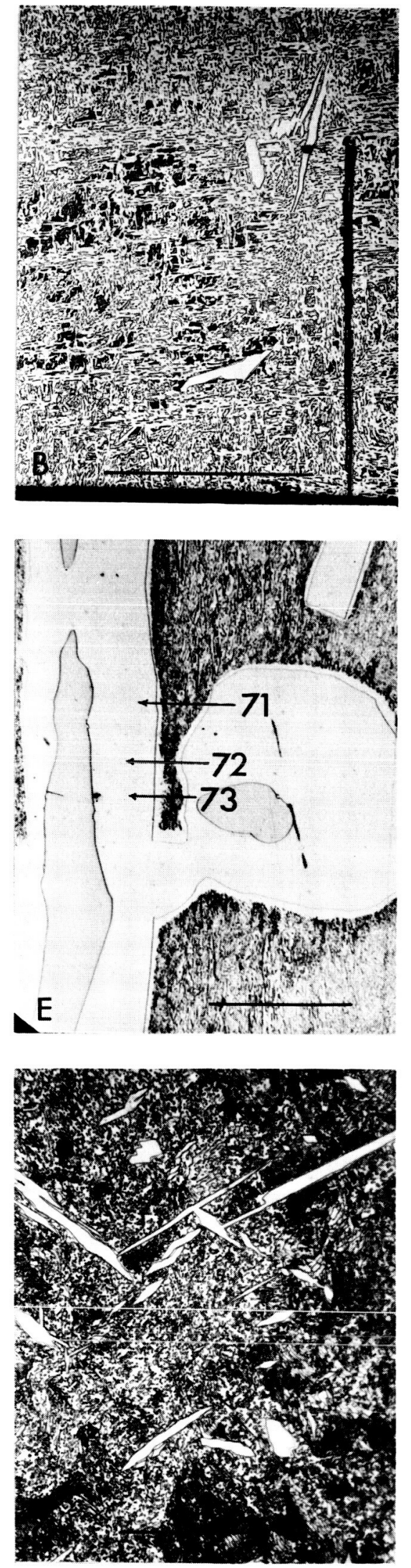
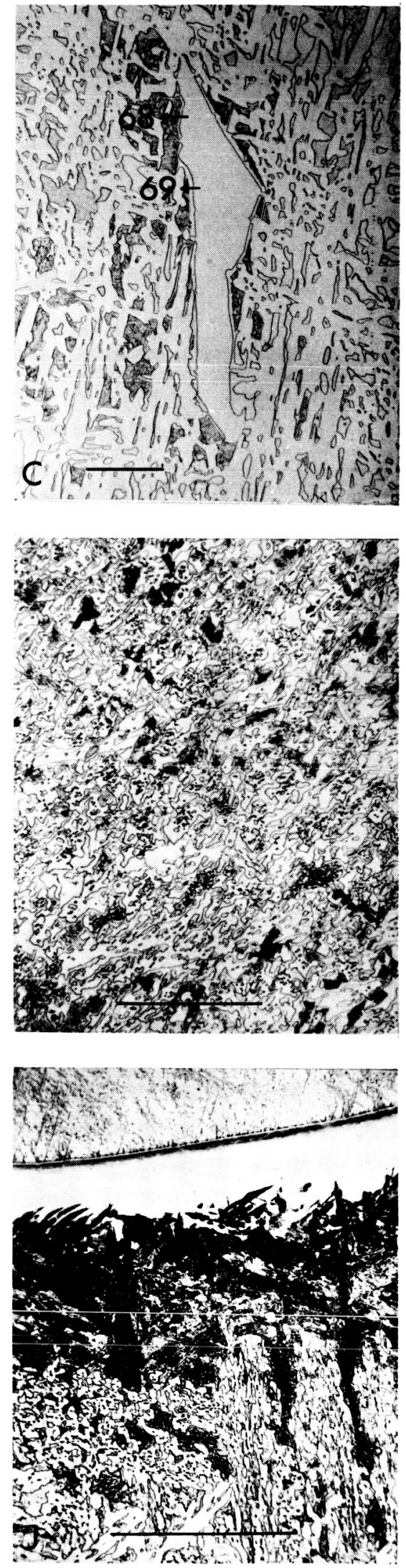


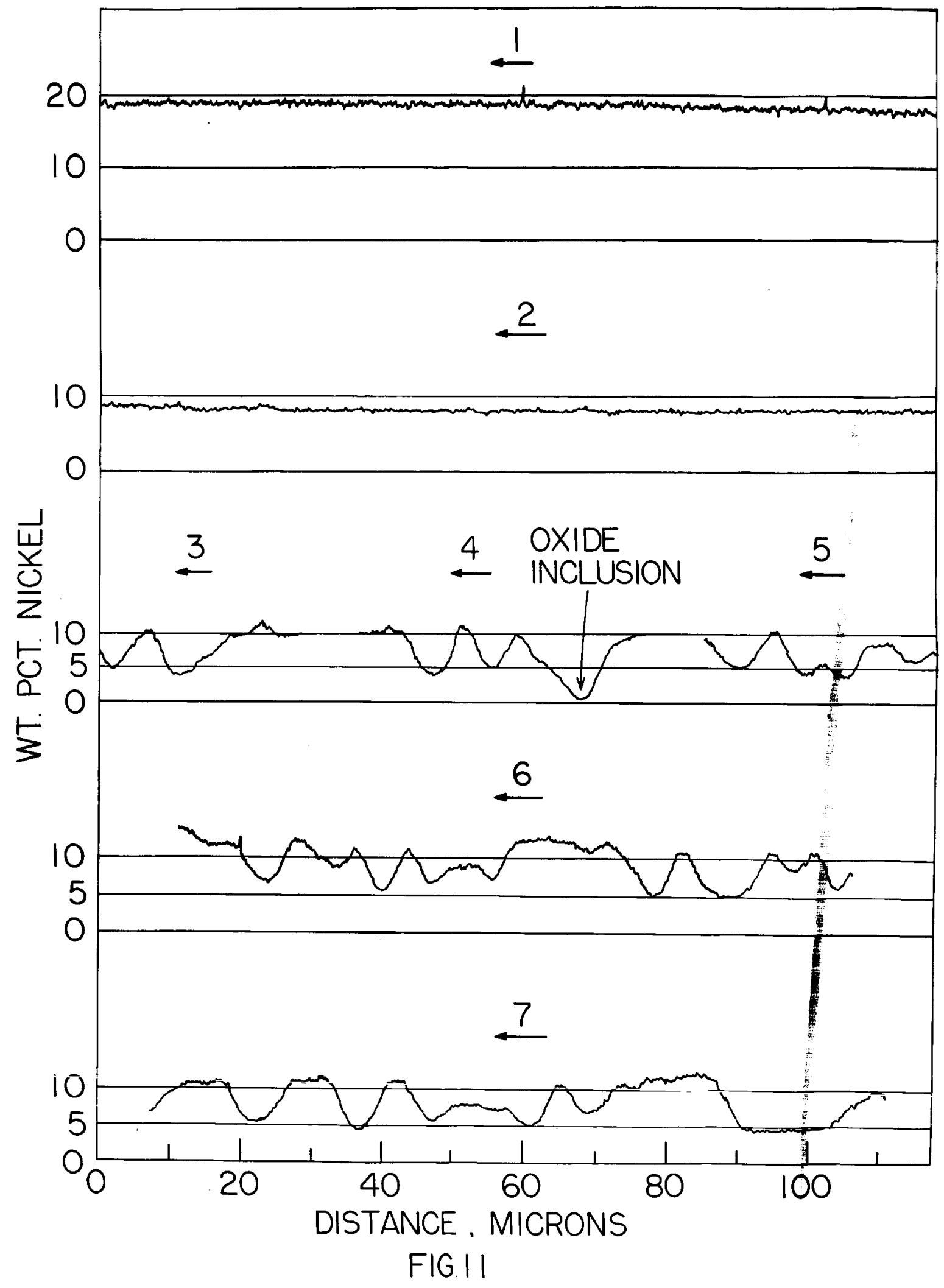




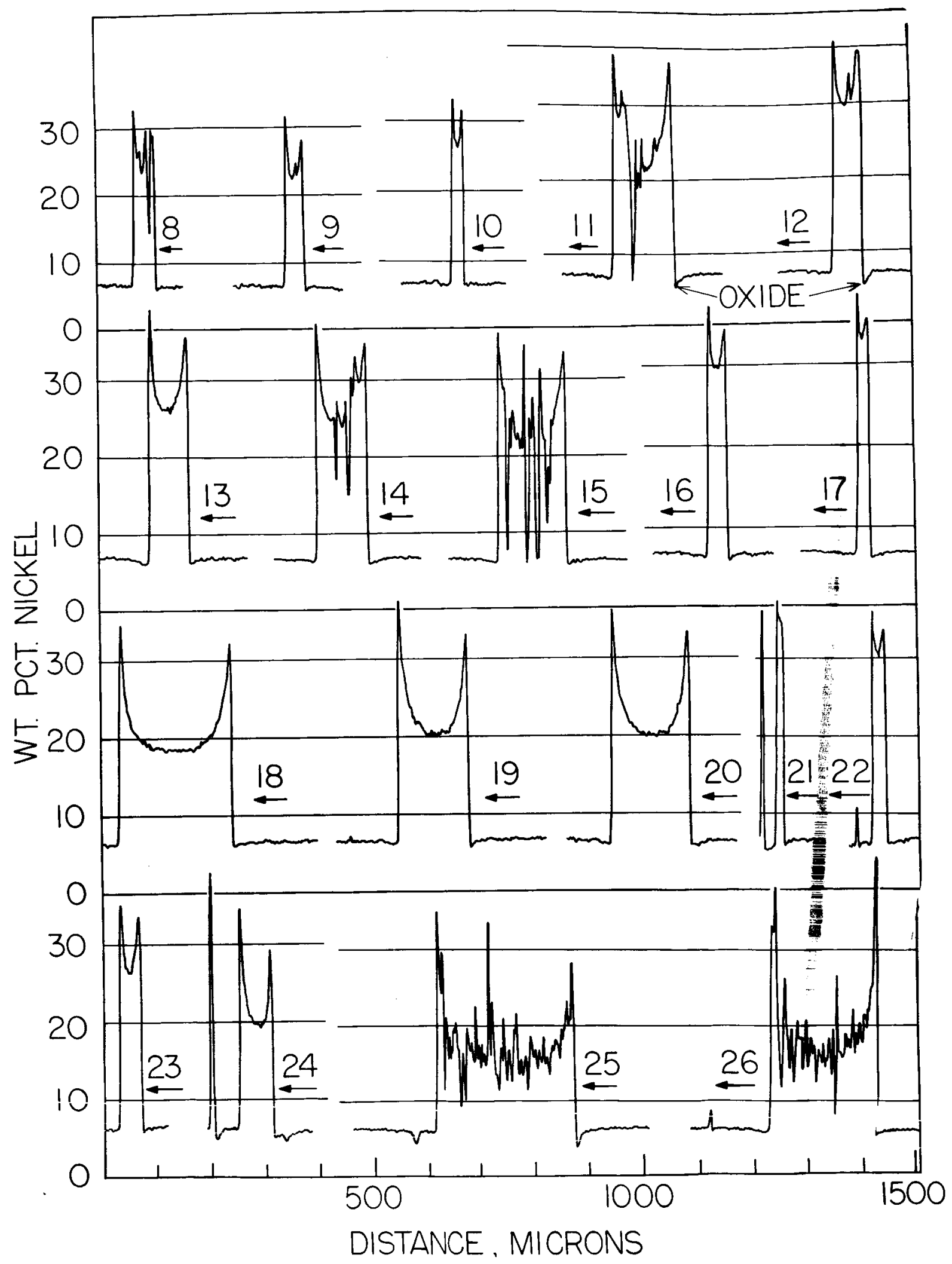

FIG.12 


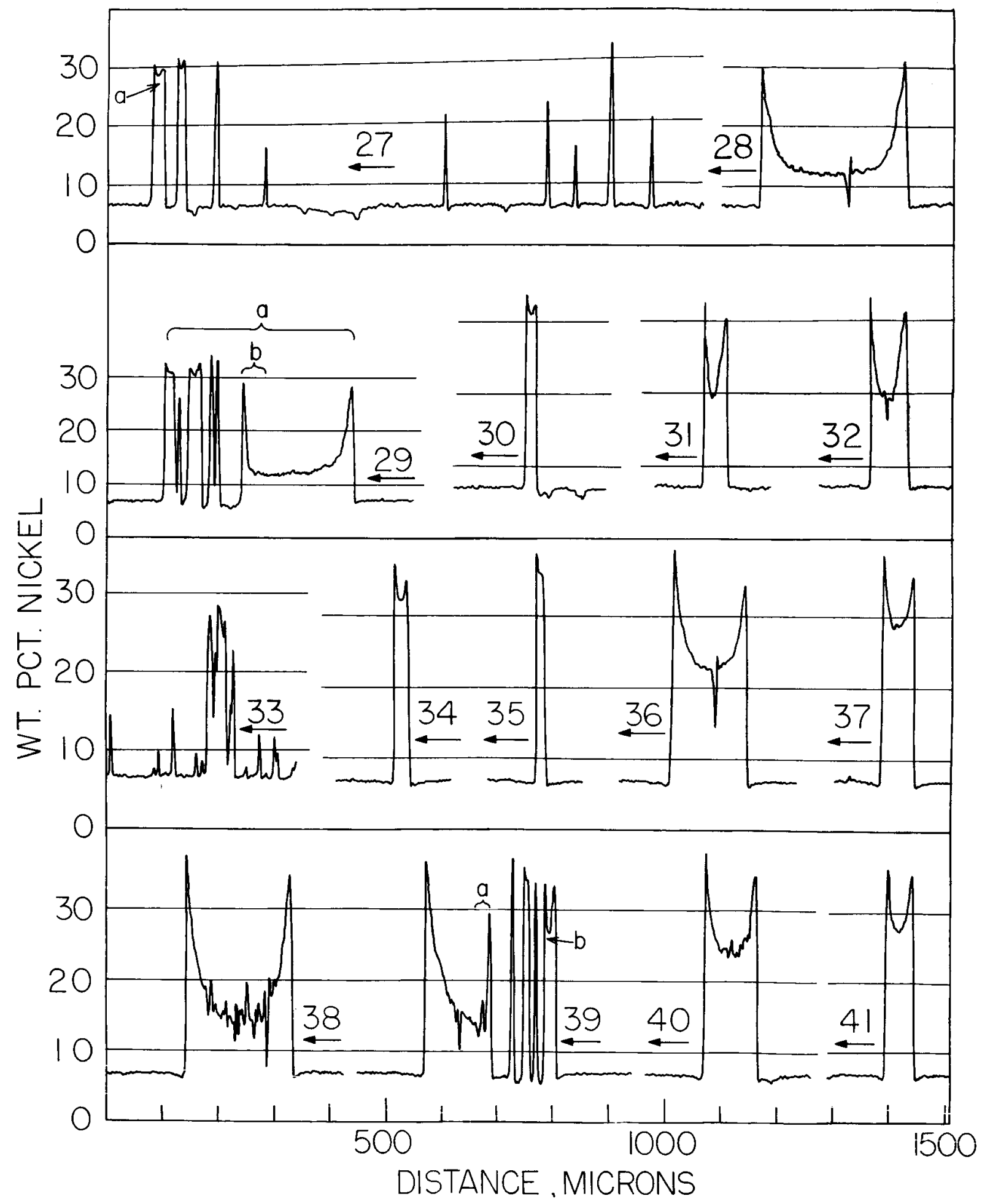

FIG 13 


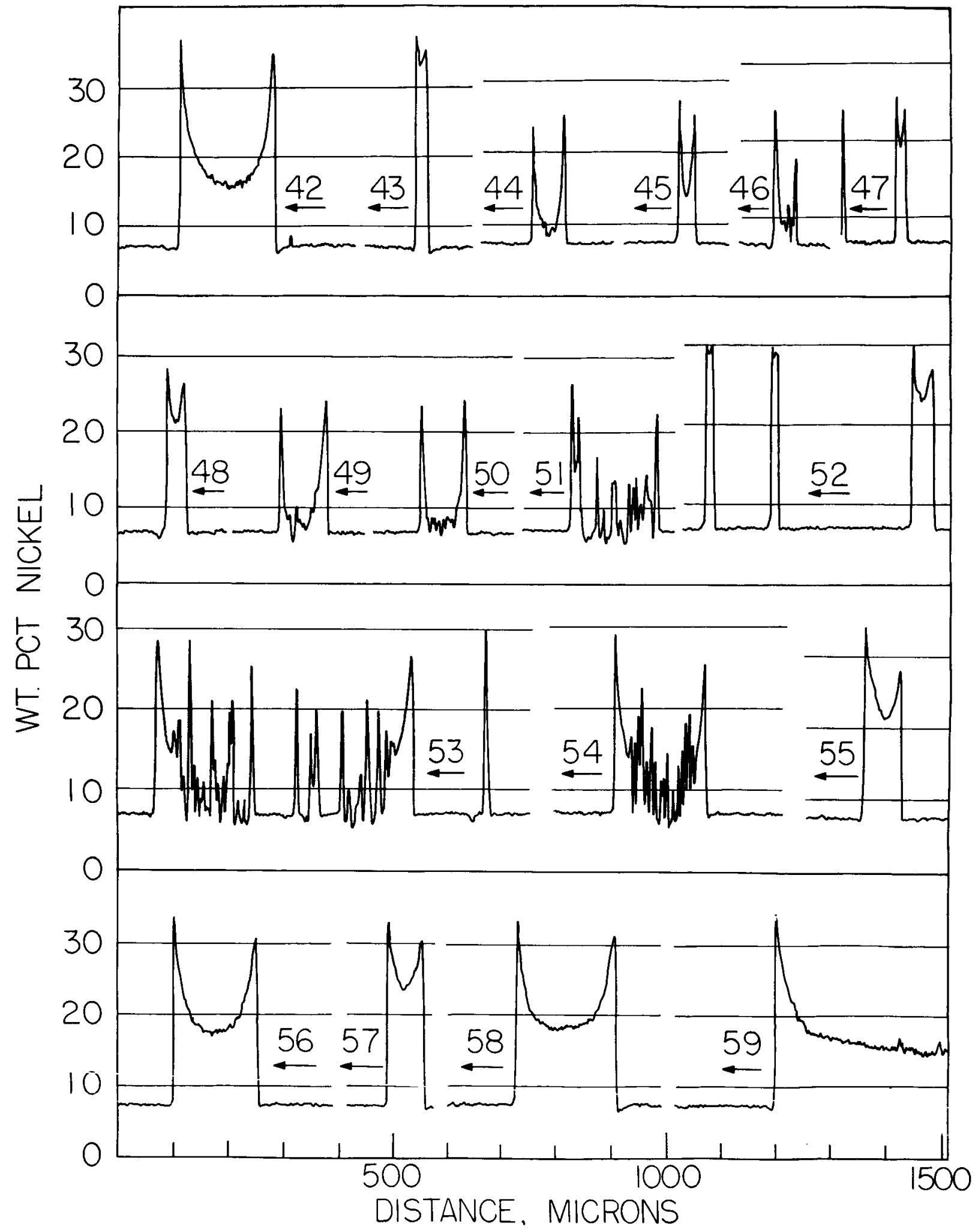

FIG 14 


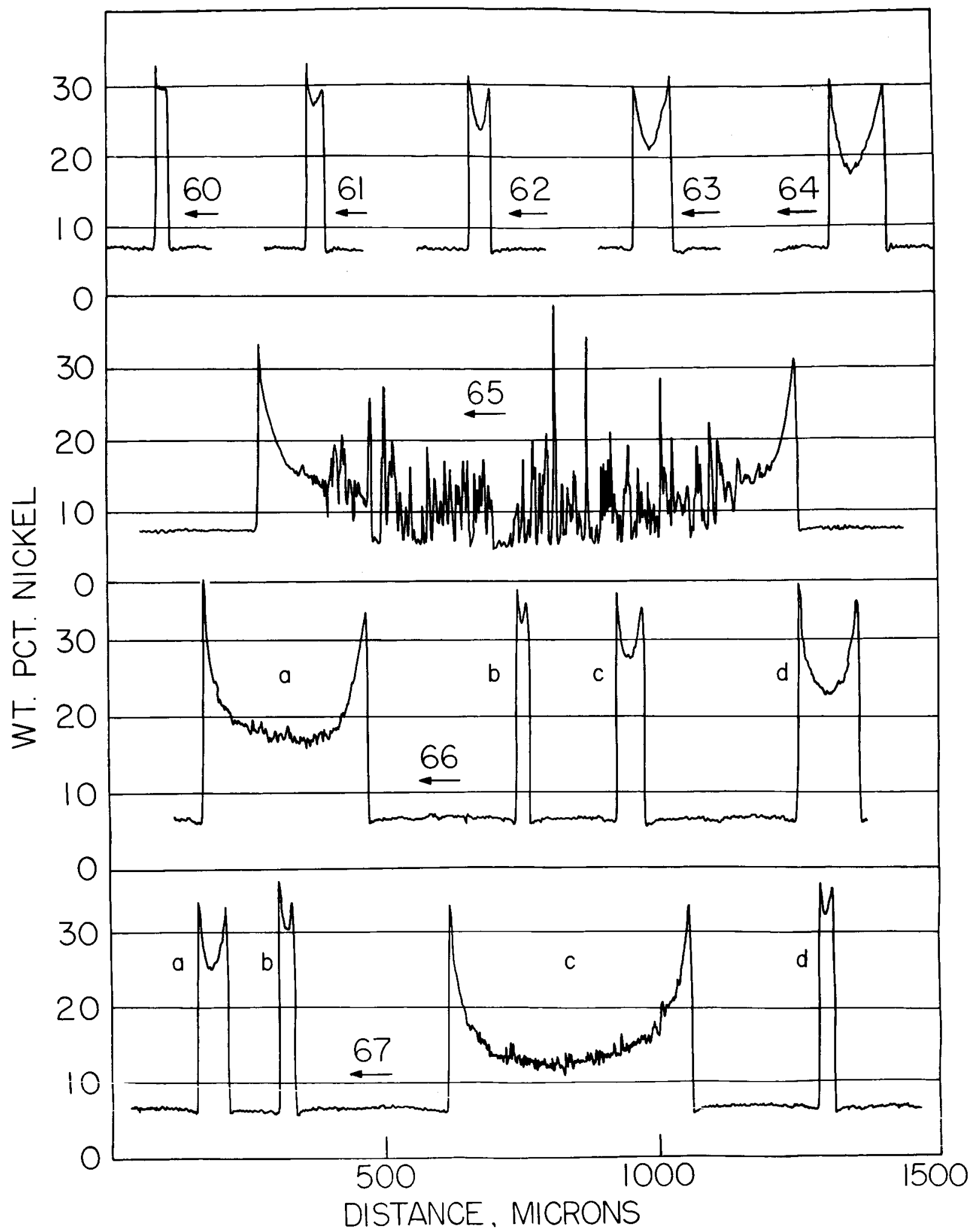

FIG. 15 

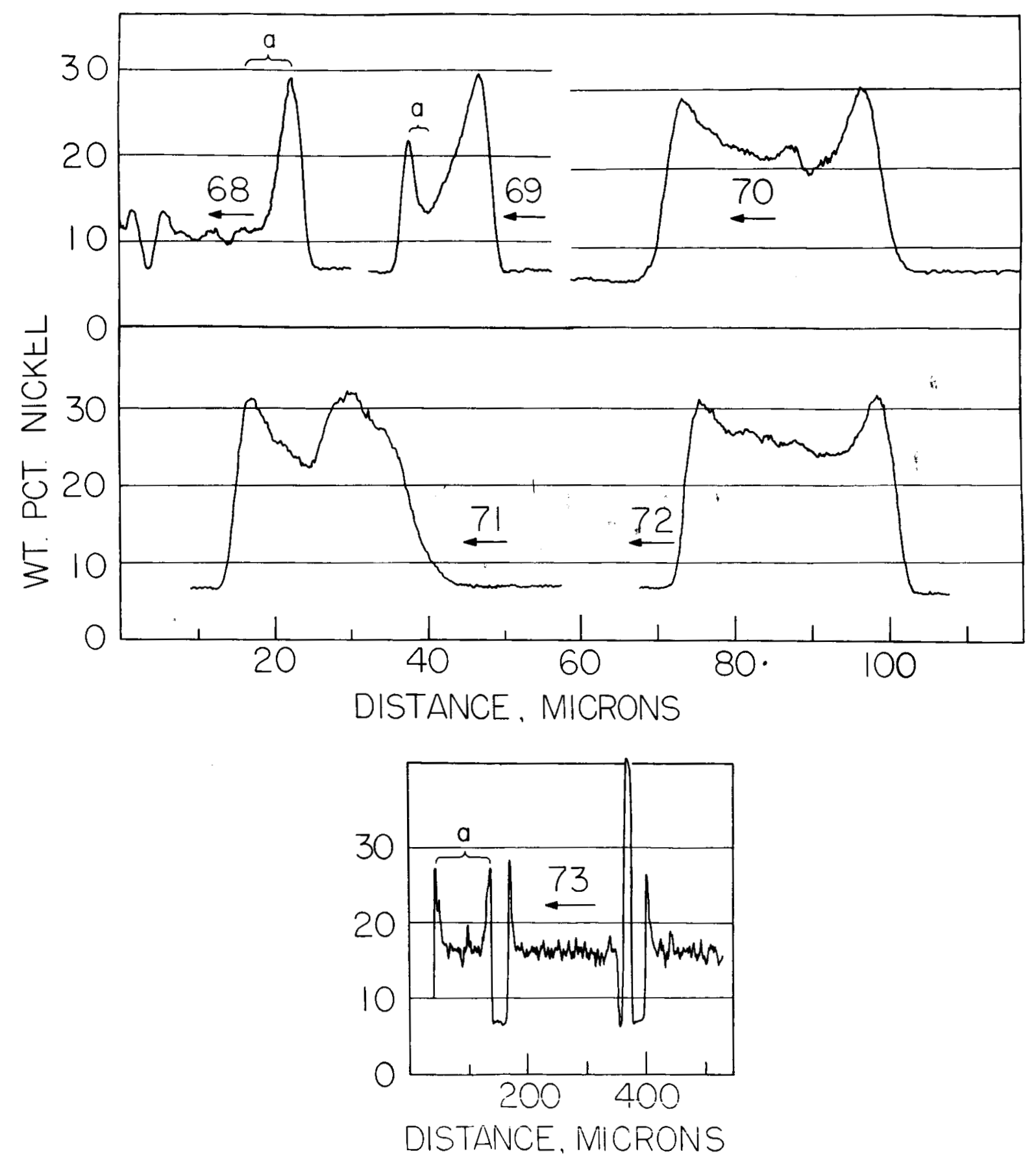

FIG 16 


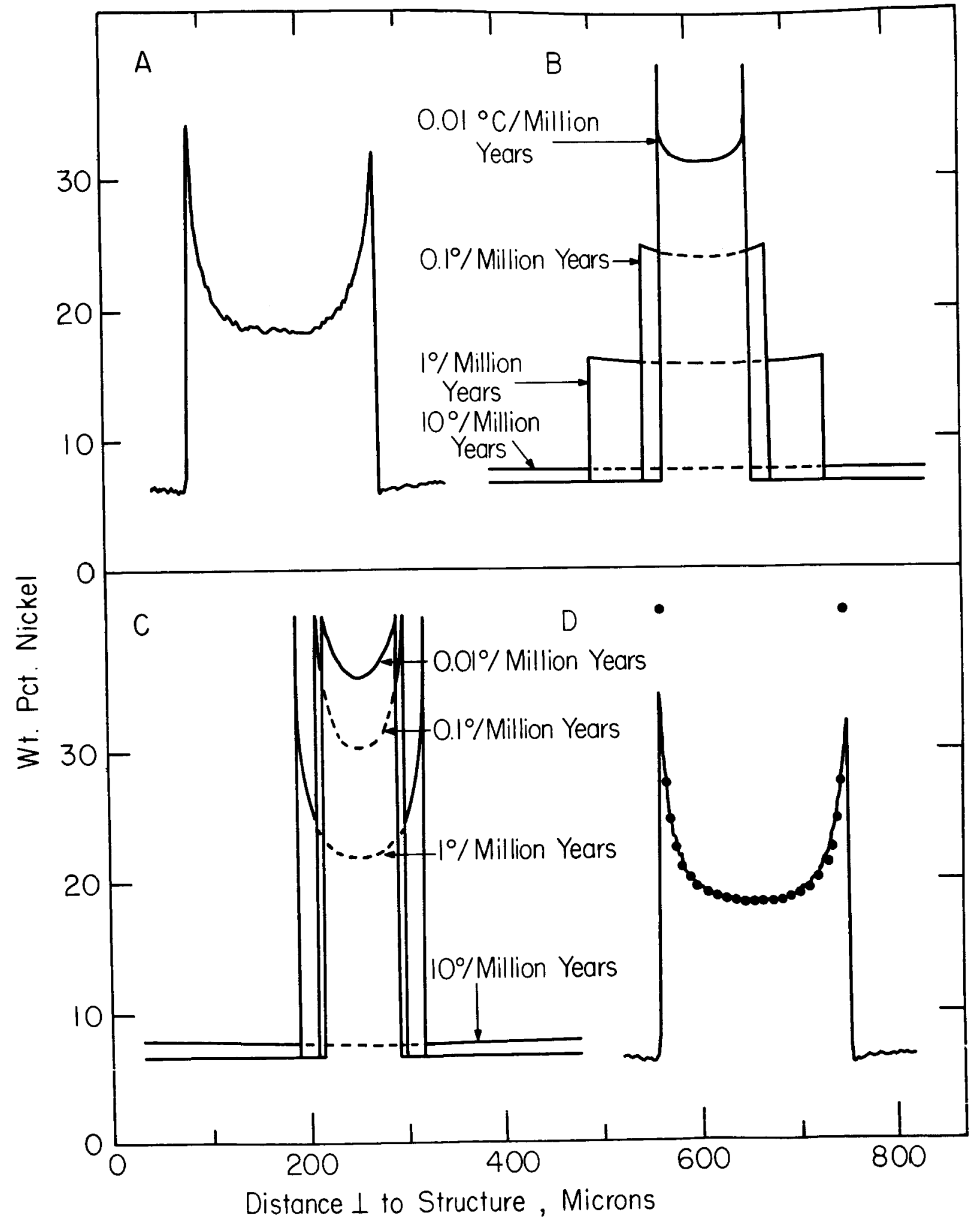

Fig. 17 


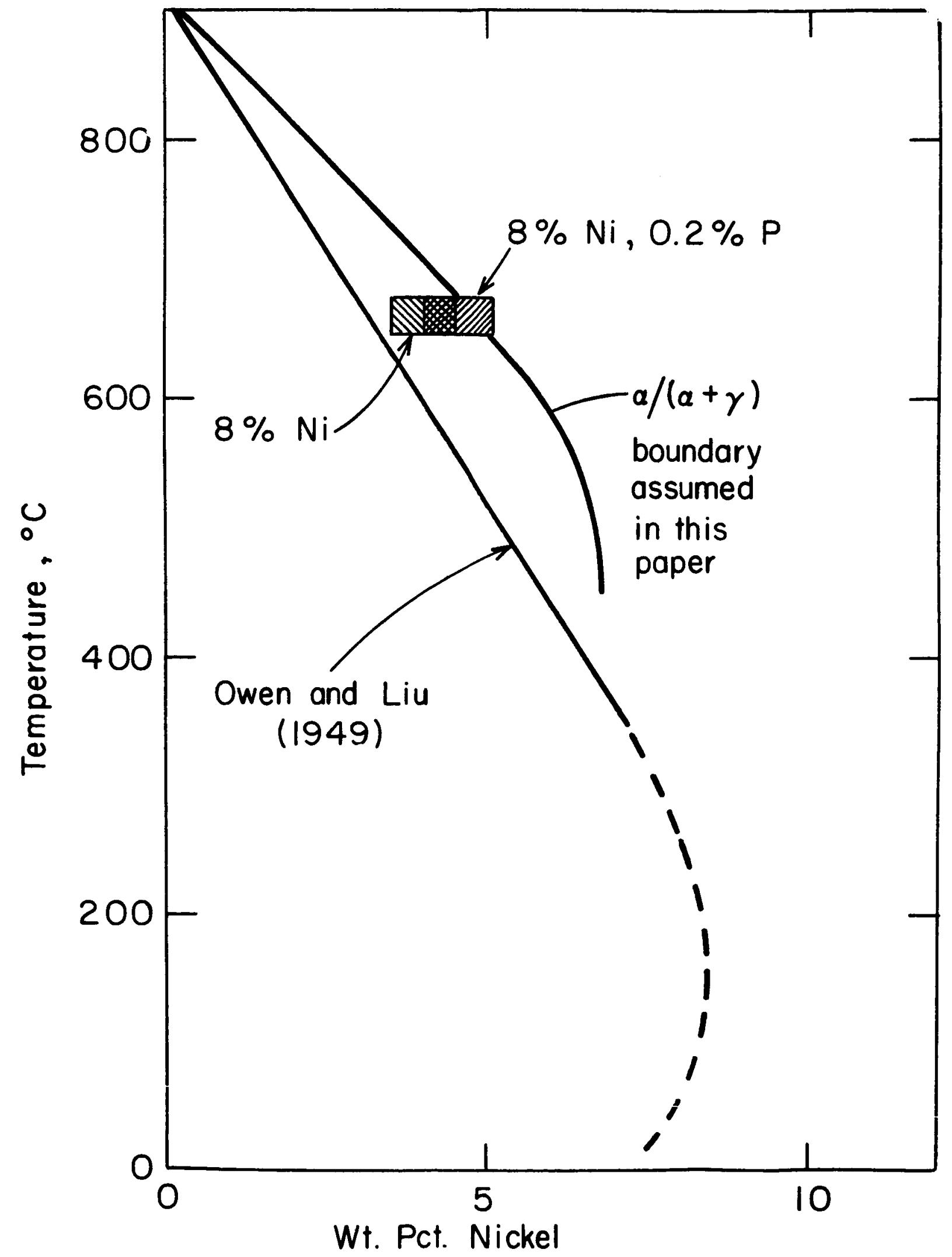

Fig. 18 


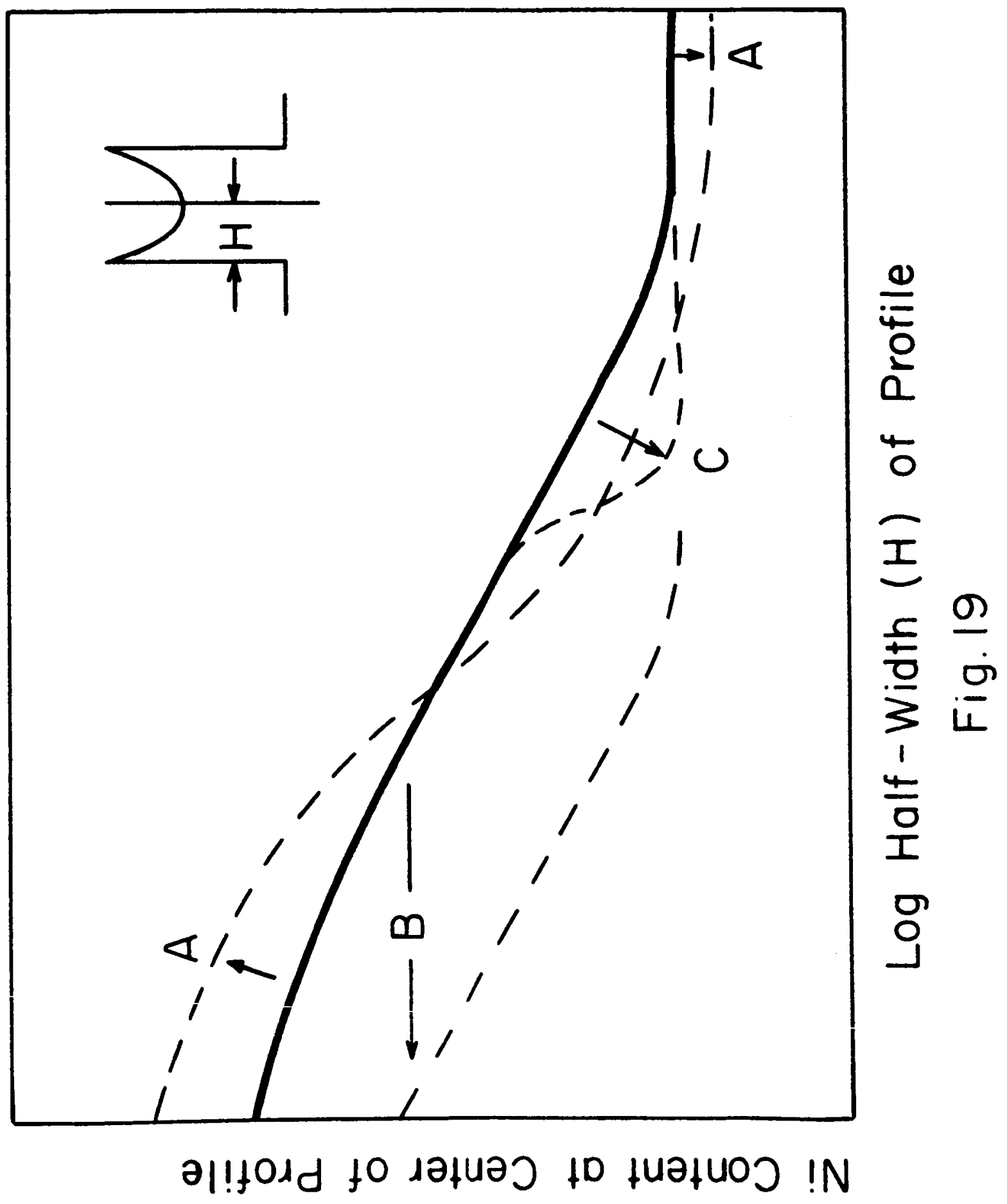



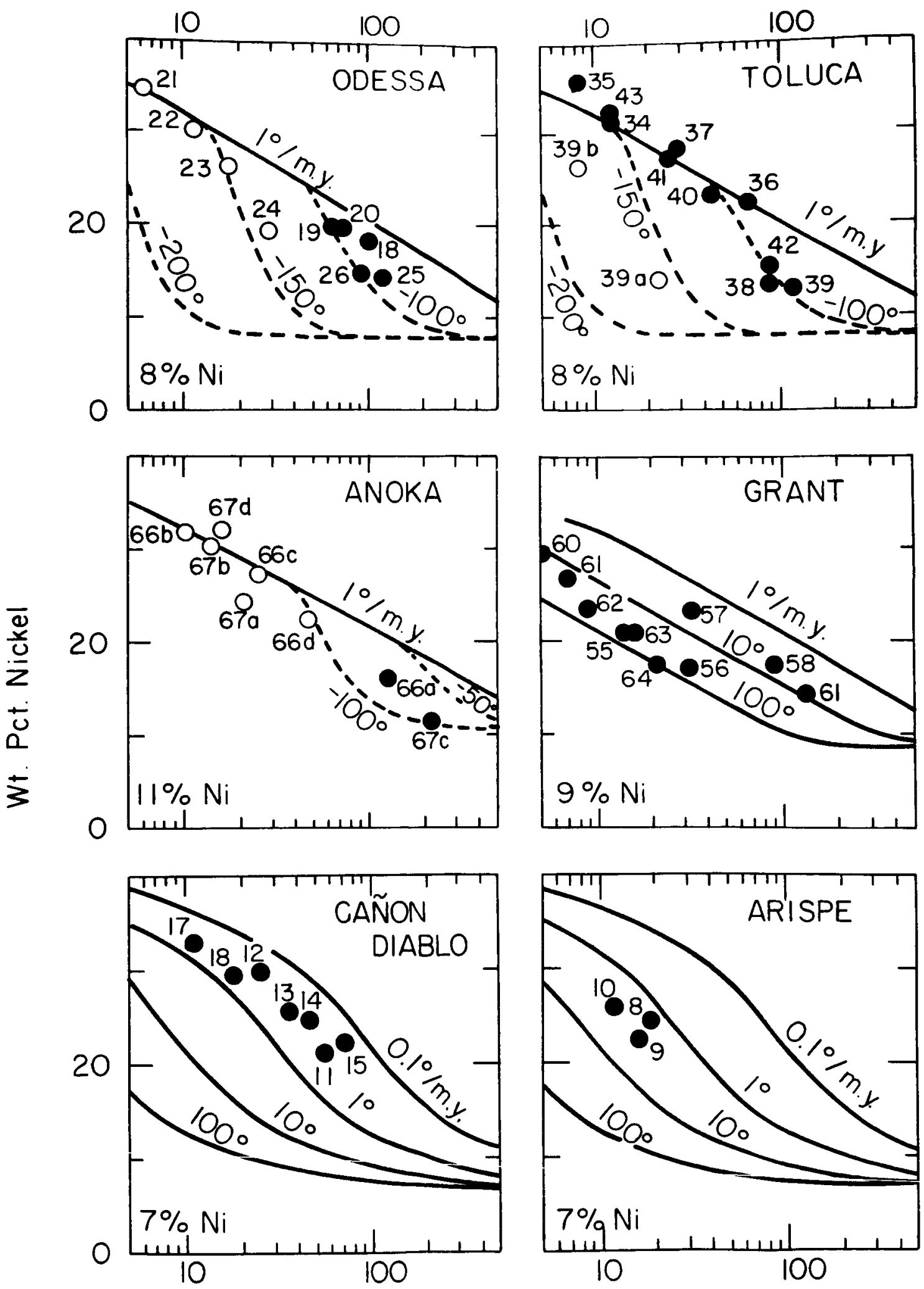

Half-Width of M-Profiles, Microns

Fig. 20 

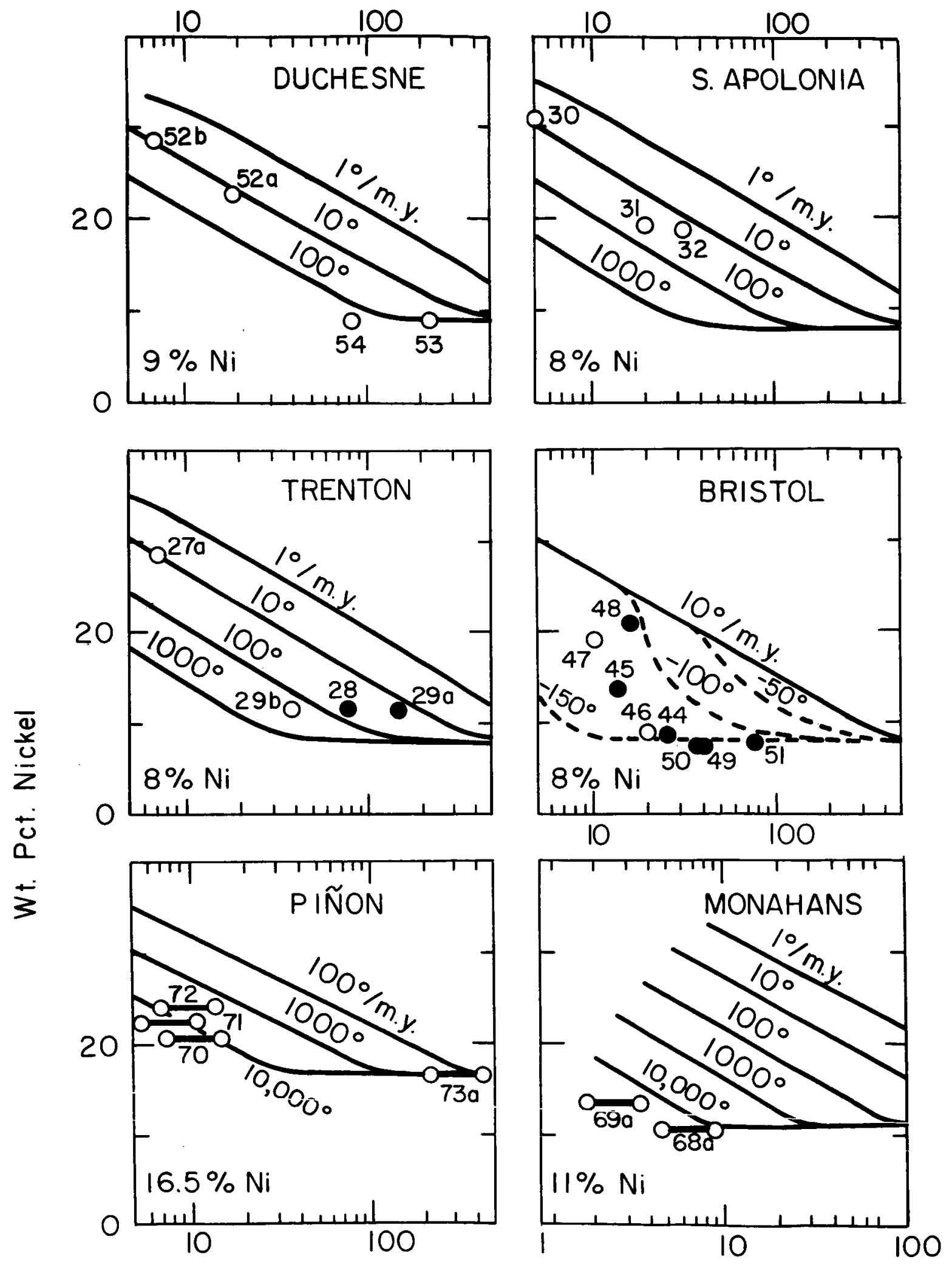

Half-Width of M-Profiles, Microns

Fig. 21 


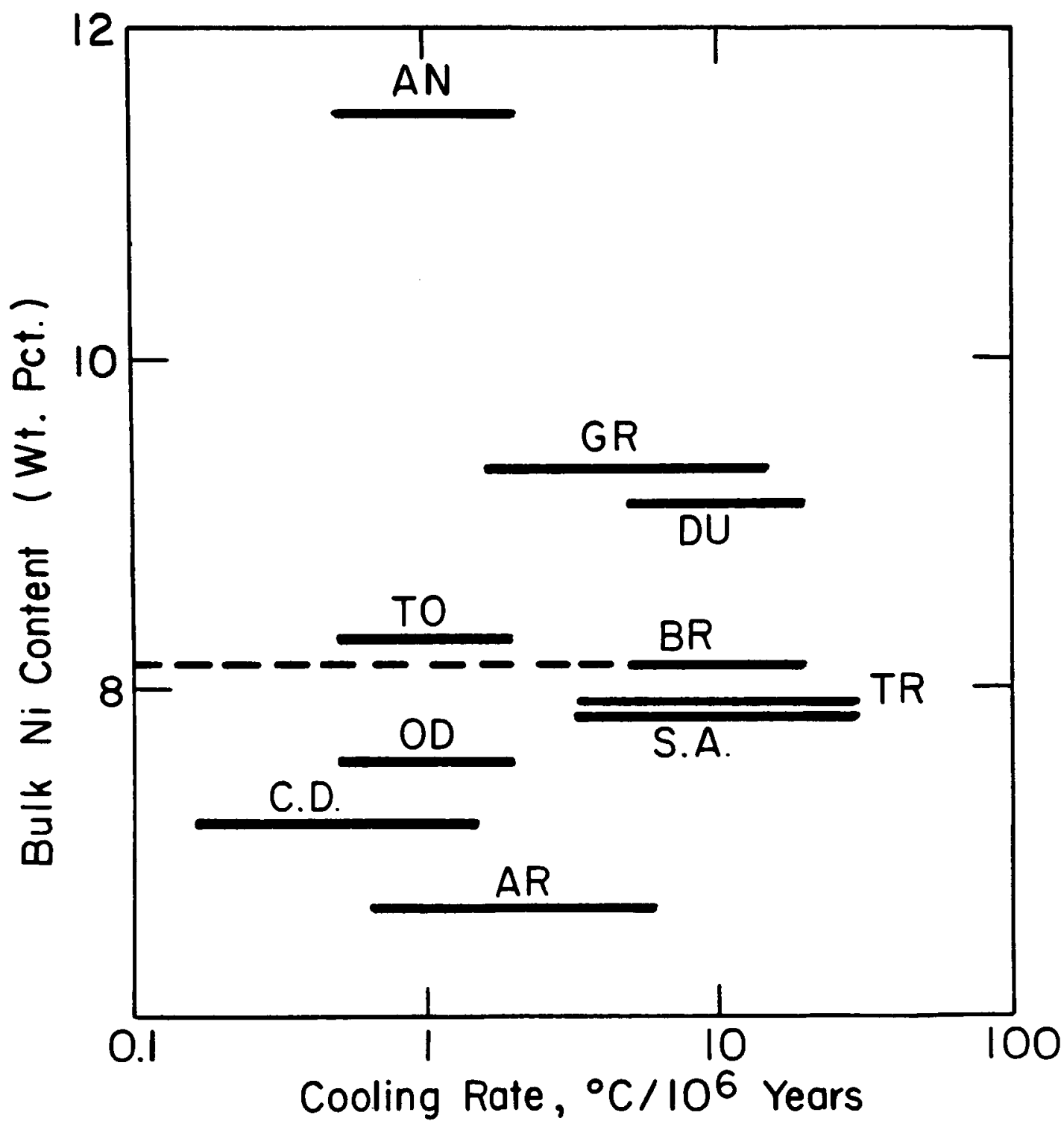

Fig. 22 


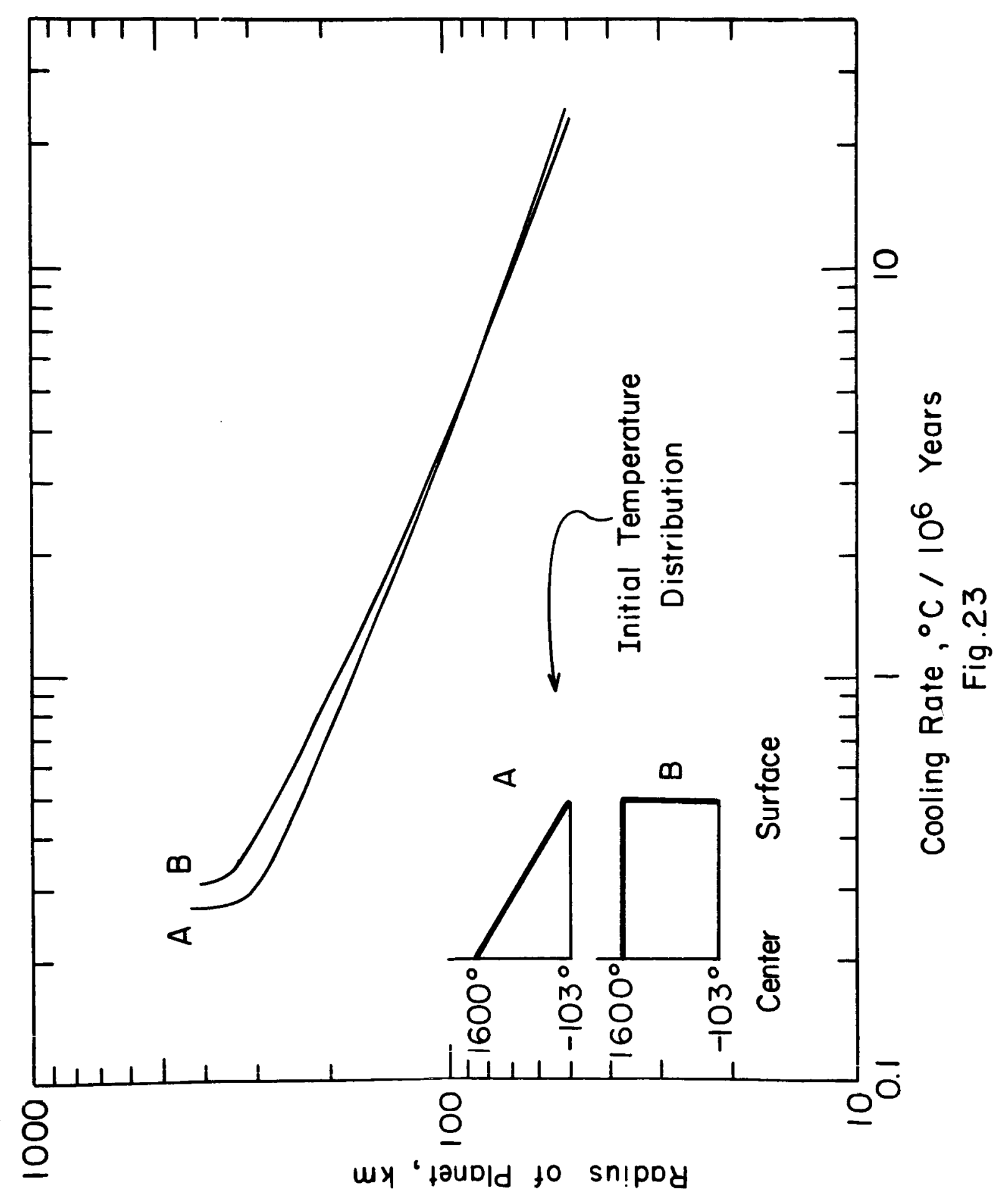




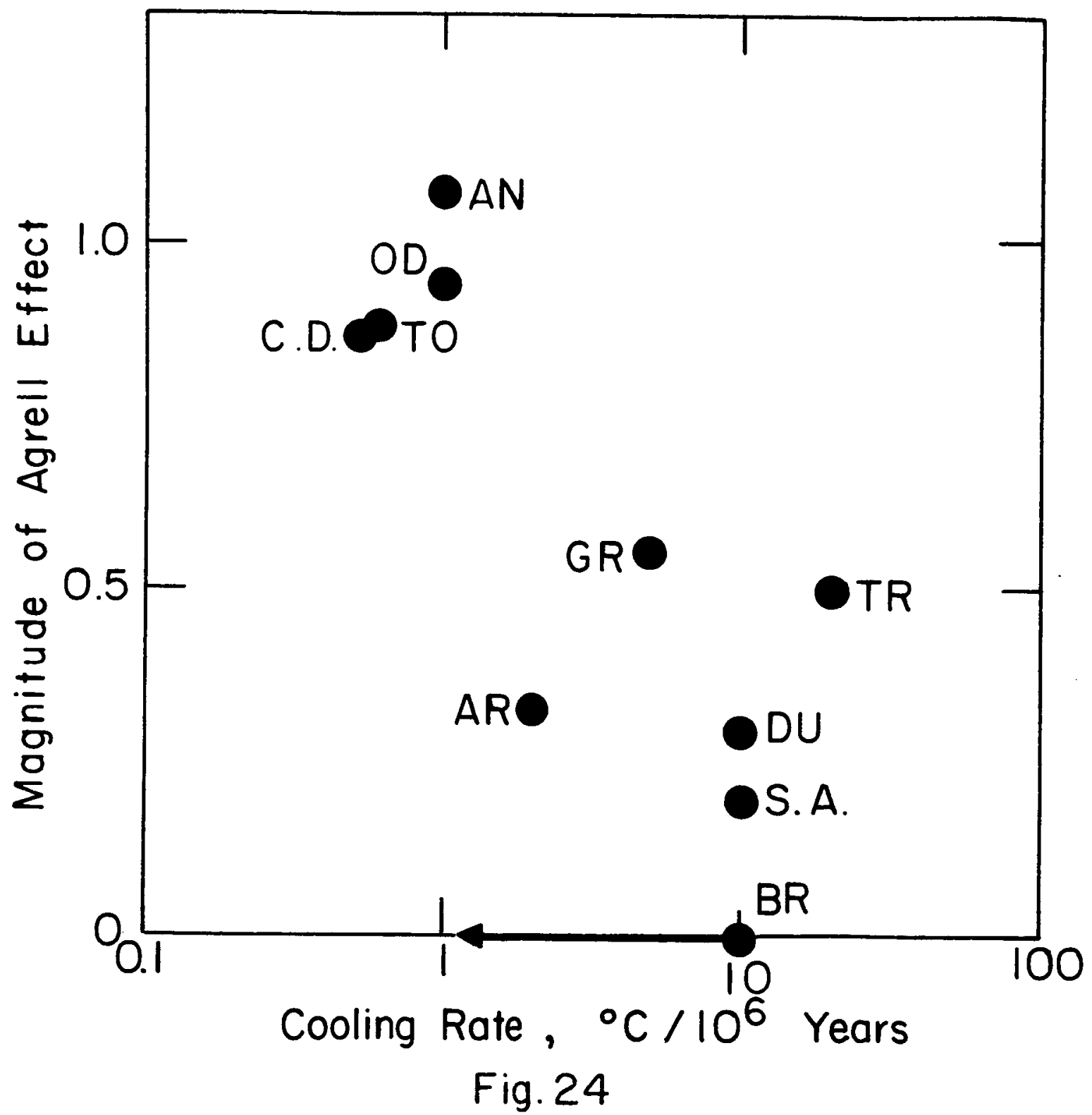



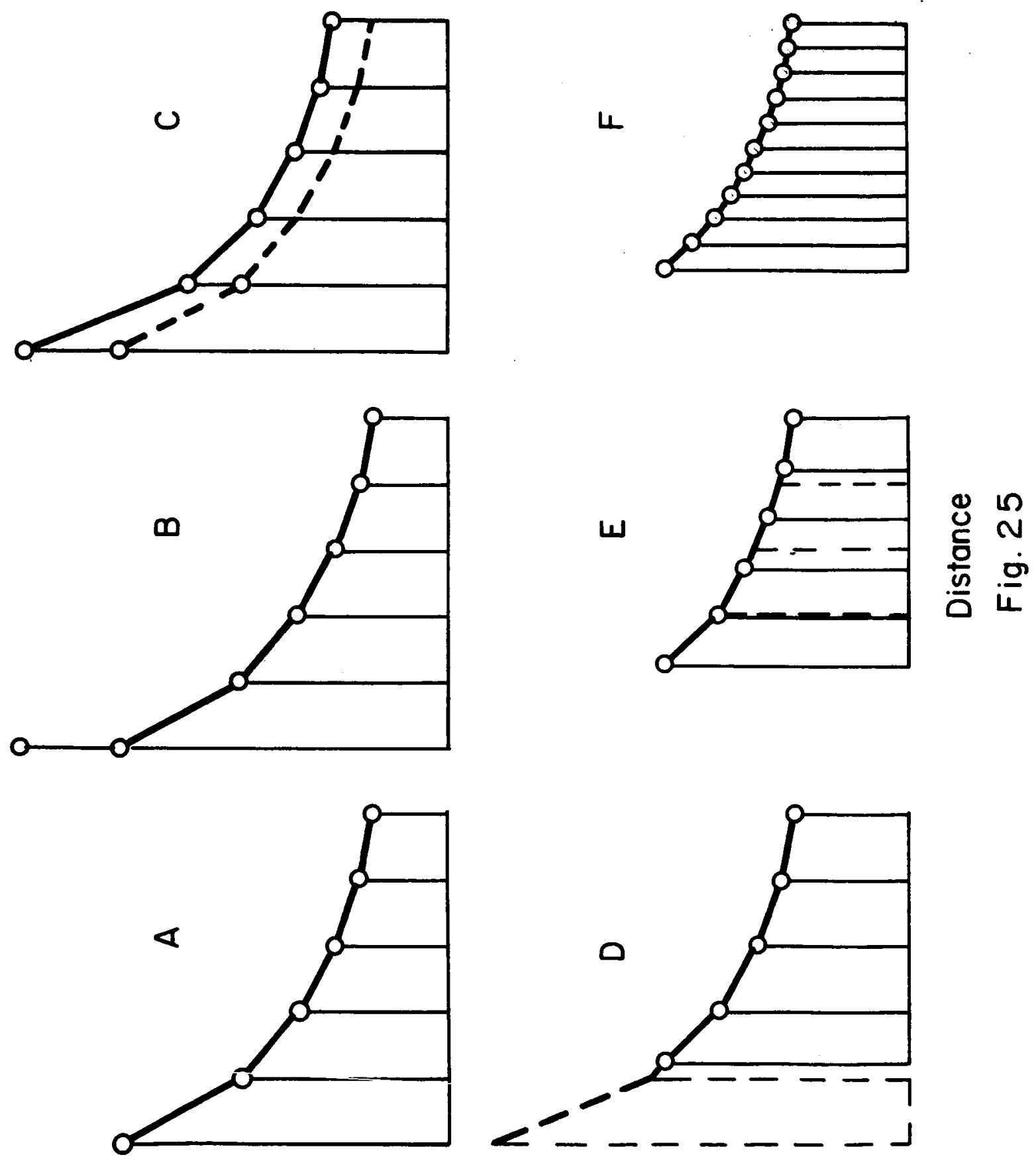

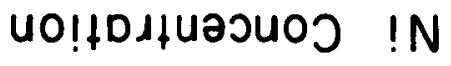




\section{ERRATUM -- About Ataxites}

The Piñon profiles in Fig. 16 are scrambled. Profile 73 in Fig. 16 corresponds with profile 70 in Fig. 10D. Profiles 70-72 in Fig. 16 do not correspond with 71-73 in Fig. 10E. The Piñon portion of Fig. 21 is incorrect.

Ni gradients in Piñon and Monahans are extremely steep. As noted in the preprint, they must have been produced by very rapid cooling, excessive supercooling, or both. To arrive at unique thermal histories for these meteorites would require that extremely small structures be profiled, smaller than the resolution of the probe beam allows.

The (correct) Ni-rich ataxite profiles are consistent with cooling at $-200^{\circ} \mathrm{m} . \mathrm{y}$. (Piñon) and $\sim 10,000^{\circ} / \mathrm{m} . \mathrm{y}$. (Monahans) if no supercooling is assumed. Additional computations have been made to determine how much supercooling would have had to occur in alloys that cooled at a more normal rate, in order to produce similarly steep profiles. The Ni-rich ataxites are members of Ga-Ge group IV. If we assume the cooling rate of $10^{\circ} / \mathrm{m} . \mathrm{y}$. indicated in this paper for other members of groups III and IV (octahedrites), it turns out that Monahans must have been supercooled by about $200^{\circ} \mathrm{C}\left(\right.$ to $\left.-470^{\circ}\right)$, Pinon by $\sim 100^{\circ}$ ( to $\sim 500^{\circ}$ ). These crystallization temperatures are about $100^{\circ}$ lower than the temperatures at which Widmanstutten structure appeared in several of the octahedrites studied, but only about $50^{\circ}$ lower than temperatures at which some late-formed kamacite crystals appeared.

It appears to me now that supercooling is more likely than rapid cooling to have caused the steep $\mathrm{Ni}$ gradients in ataxites. If piñon had cooled rapidly, plessite in it should be finer than plessite of comparable composition in the octahedrites, according to the mechanism of plessite formation developed in section 5 . In fact, Piñon plessite appears to be comparable in coarseness to plessite in Odessa and Toluca (Fig. 10E vs. Figs. 10G and H). 